\title{
Mitochondria-targeted accumulation of oxygen-irrelevant free radicals for enhanced synergistic low-temperature photothermal and thermodynamic therapy
}

Hongzhi Hu ${ }^{1,3,4+}$, Xiangtian Deng ${ }^{2+}$, Qingcheng Song ${ }^{3,4+}$, Wenbo Yang ${ }^{1}$, Yiran Zhang ${ }^{2}$, Weijian Liu 1,3,4, Shangyu Wang ${ }^{1}$, Zihui Liang ${ }^{5}$, Xin Xing ${ }^{3,4}$, Jian Zhu², Junzhe Zhang ${ }^{2,3,4}$, Zengwu Shao $^{1 *}$, Baichuan Wang $^{1 *}$ and Yingze Zhang $1,3,4^{*}$

\begin{abstract}
Background: Although lower temperature $\left(<45^{\circ} \mathrm{C}\right)$ photothermal therapy (LPTT) have attracted enormous attention in cancer therapy, the therapeutic effect is still unsatisfying when applying LPTT alone. Therefore, combining with other therapies is urgently needed to improve the therapeutic effect of LPTT. Recently reported oxygen-irrelevant free radicals based thermodynamic therapy (TDT) exhibit promising potential for hypoxic tumor treatment. However, overexpression of glutathione (GSH) in cancer cells would potently scavenge the free radicals before their arrival to the specific site and dramatically diminish the therapeutic efficacy.

Methods and results: In this work, a core-shell nanoplatform with an appropriate size composed of arginine-glycine-aspartate (RGD) functioned polydopamine (PDA) as a shell and a triphenylphosphonium (TPP) modified hollow mesoporous manganese dioxide $\left(\mathrm{H}-\mathrm{mMnO}_{2}\right)$ as a core was designed and fabricated for the first time. This nanostructure endows a size-controllable hollow cavity $\mathrm{mMnO}_{2}$ and thickness-tunable PDA layers, which effectively prevented the pre-matured release of encapsulated azo initiator 2,2'-azobis[2-(2-imidazolin-2-yl) propane] dihydrochloride (AIBI) and revealed $\mathrm{pH} / \mathrm{NIR}$ dual-responsive release performance. With the mitochondria-targeting ability of TPP, the smart nanocomposites (AIBI@H-mMnO 2 -TPP@PDA-RGD, AHTPR) could efficiently induce mitochondrial associated apoptosis in cancer cells at relatively low temperatures $\left(<45^{\circ} \mathrm{C}\right)$ via selectively releasing oxygen-irrelevant free radicals in mitochondria and facilitating the depletion of intracellular GSH, exhibiting the advantages of mitochondria-targeted LPTT/TDT. More importantly, remarkable inhibition of tumor growth was observed in a subcutaneous xenograft model of osteosarcoma (OS) with negligible side effects.
\end{abstract}

Conclusions: The synergistic therapy efficacy was confirmed by effectively inducing cancer cell death in vitro and completely eradicating the tumors in vivo. Additionally, the excellent biosafety and biocompatibility of the

\footnotetext{
*Correspondence: szwpro@163.com; wangbaichuan-112@163.com; yzling_liu@163.com

†Hongzhi Hu, Xiangtian Deng, and Qingcheng Song have equally contributed to this work

${ }^{1}$ Department of Orthopaedics, Union Hospital, Tongji Medical College, Huazhong University of Science and Technology, Wuhan 430022, China

Full list of author information is available at the end of the article
} permits use, sharing, adaptation, distribution and reproduction in any medium or format, as long as you give appropriate credit to the original author(s) and the source, provide a link to the Creative Commons licence, and indicate if changes were made. The images or other third party material in this article are included in the article's Creative Commons licence, unless indicated otherwise in a credit line to the material. If material is not included in the article's Creative Commons licence and your intended use is not permitted by statutory regulation or exceeds the permitted use, you will need to obtain permission directly from the copyright holder. To view a copy of this licence, visit http://creativecommons.org/licenses/by/4.0/. The Creative Commons Public Domain Dedication waiver (http://creativeco mmons.org/publicdomain/zero/1.0/) applies to the data made available in this article, unless otherwise stated in a credit line to the data. 
nanoplatforms were confirmed both in vitro and in vivo. Taken together, the current study provides a novel paradigm toward oxygen-independent free-radical-based cancer therapy, especially for the treatment of hypoxic solid tumors.

Keywords: Low temperature photothermal therapy, Thermodynamic therapy, Mitochondria-targeting, $\mathrm{MnO}_{2}$ nanoparticle, Oxygen-irrelevant free radicals, Azo initiator

\section{Graphical Abstract}

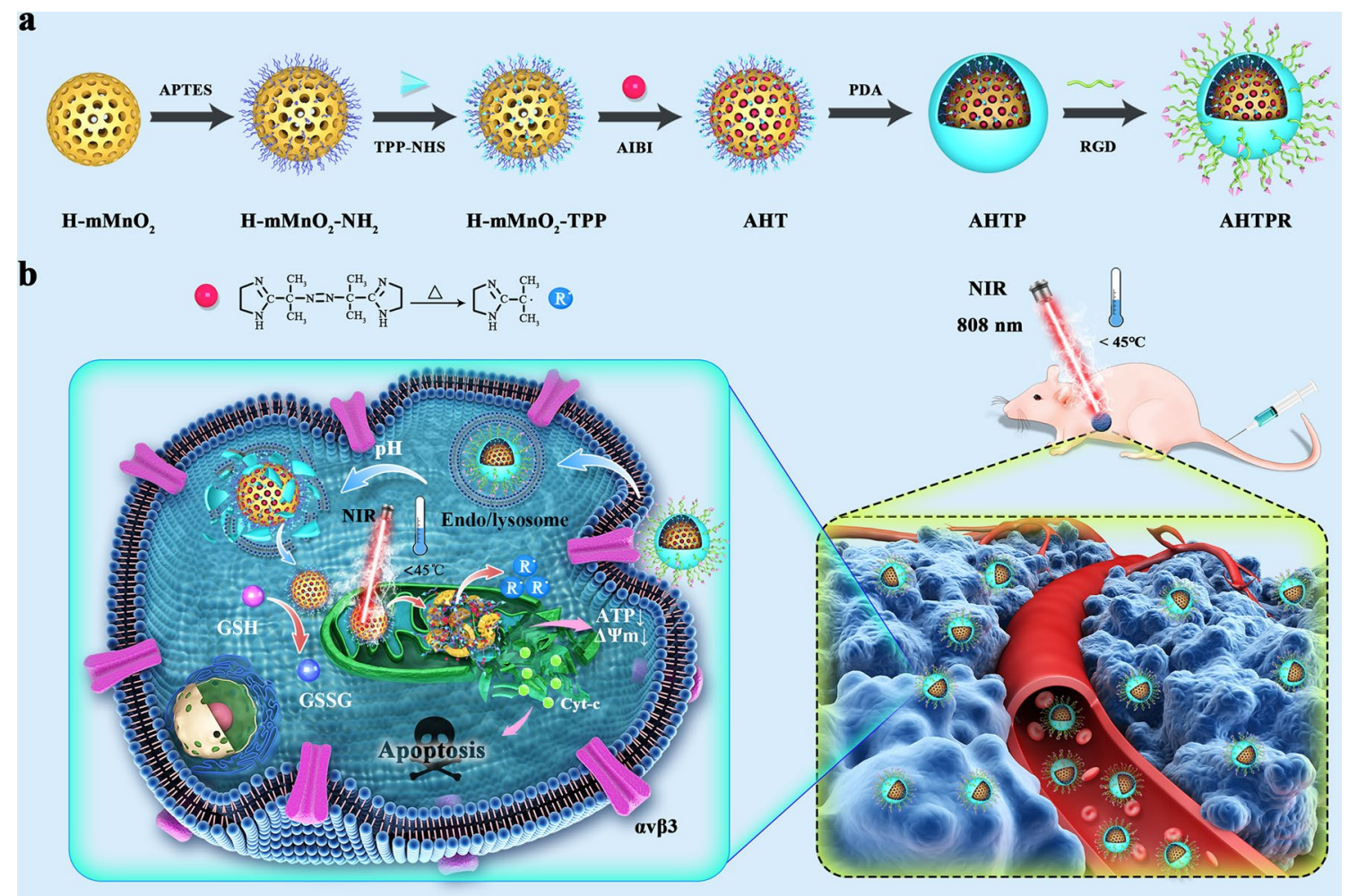

\section{Introduction}

Photothermal therapy (PTT) has recently emerged as a promising cancer therapeutic strategy due to its merits of noninvasiveness, specific spatiotemporal selectivity, and negligible drug resistance [1, 2]. Generally, PTT heavily depends on a high power intensity near-infrared laser (NIR) irradiation to ensure therapeutic efficacy, which inevitably damages the nearby normal tissues [3]. Recently, developing a PTT strategy with relatively low temperatures $\left(<45{ }^{\circ} \mathrm{C}\right)$ to realize effective tumor destruction can be very important for clinical translation in the future $[4,5]$. However, the therapeutic effect is still unsatisfying when applying low-temperature PTT (LPTT) alone, which is ascribed to inducible heat resistance of cancer cells, poor penetration of exogenous light stimulation, and low accumulation of photothermal agents in tumor sites [6]. Therefore, it is highly desirable to combine with other therapies to improve the therapeutic effect of LPTT.
Reactive oxygen species (ROS)-based cancer dynamic therapy, such as chemodynamic therapy (CDT) [7], photodynamic therapy (PDT) [8], sonodynamic therapy (SDT) [9], has attracted tremendous attention in recent years. Unfortunately, the performance of these oxygendependent anticancer modalities is seriously compromised by the hypoxic tumor microenvironment at solid tumors [4]. In accordance with the problem, enormous efforts have been made including intra-tumoral oxygen delivery [10] or oxygen production in situ [11]. Nevertheless, these strategies still could not move away from the dependence on oxygen fundamentally. In this regard, an ingenious strategy by using oxygen-irrelevant free radicals is expected to achieve effective antitumor thermodynamic therapy (TDT) under mild thermal stimulation [4, $12,13]$. Thermal-labile azo initiators, such as azo initiator 2,2'-azobis[2-(2-imidazolin-2-yl) propane] dihydrochloride (AIBI), can be decomposed rapidly into highly reactive alkyl radicals under mild heat stimulation without oxygen participation [13, 14]. However, the efficacy 
induced by the free radicals is spatially and temporally restricted due to their short lifetime and confined diffusion distance [15]. Endeavoring free radicals with subcellular organelle targeting ability might dramatically enhance their therapeutic efficacy. Thus, selectively generation of free radicals in mitochondria may significantly enhance the efficacy of the TDT because mitochondria are susceptible to free-radical mediated damages [15]. Unfortunately, intracellular overexpression of glutathione (GSH) in cancer cells, which might potently inactive the alkyl radicals, dramatically diminished the therapeutic efficacy [16]. Therefore, we intend to develop a smart therapy strategy, which can not only selectively accumulate free radicals in mitochondria but also simultaneously consume the intracellular GSH, to achieve synergistically enhanced LPTT/TDT.

Manganese dioxide $\left(\mathrm{MnO}_{2}\right)$ nanostructures have recently aroused great interest as a unique type of TMEresponsive nanomaterial [17]. $\mathrm{MnO}_{2} \mathrm{NPs}$ can facilitate GSH oxidation to yield glutathione disulfide (GSSG), thus effectively depleting the intracellular GSH $[18,19]$. In addition, $\mathrm{MnO}_{2} \mathrm{NPs}$ exhibited excellent photothermal conversion efficiency, with great potential to completely ablate tumors under NIR irradiation. However, most previously reported $\mathrm{MnO}_{2}$ nanostructures are in the form of nanosheets and nanoparticles, which may not be ideal to realize drug delivery or accurately controlling drug release [20, 21]. Recently, hollow mesoporous $\mathrm{MnO}_{2}$ $\left(\mathrm{H}-\mathrm{mMnO}_{2}\right)$ nanostructures have been extensively studied as an excellent drug loading/delivery system due to their loading efficiency and prominent biodegradability $[18,22,23]$. In order to achieve "zero release", one promising strategy is to block the pores of $\mathrm{H}-\mathrm{mMnO}_{2}$ using gatekeepers. Polydopamine (PDA), a mussel-inspired material, has strong adhesion so that it could be coated on the surface of various materials under slightly alkaline conditions [24]. Of note, PDA shell could be depolymerized to release encapsulated drugs in an acid environment, avoiding undesirable premature drug leakage during circulation in the blood [23]. In addition, the rich chemical groups on the PDA surface enable it to achieve further functionalization. With these findings in mind, we hypothesized PDA coated $\mathrm{H}-\mathrm{mMnO}_{2} \mathrm{NPs}$ with versatile designs have the potential to achieve precisely targeted delivery of azo initiators while efficiently depleting intracellular GSH.

Herein, we, for the first time, rationally designed an intelligent core-shell nanoplatform based on $\mathrm{H}-\mathrm{mMnO}_{2}$ for tumor-targeted drug delivery, $\mathrm{pH}$-triggered controllable release and mitochondrial targeting accumulation of free radicals, so as to achieve synergistically enhanced LPTT/TDT. As illustrated in Scheme 1a, $\mathrm{H}-\mathrm{mMnO}_{2}$ NPs were firstly prepared as previously described with mild modification. Mitochondria-targeting ligands triphenylphosphine (TPP) was then modified on the surface of $\mathrm{H}-\mathrm{mMnO}_{2}$ to construct the $\mathrm{H}-\mathrm{mMnO}_{2}$-TPP. Subsequently, the azo initiator AIBI was encapsulated into $\mathrm{H}-\mathrm{mMnO}_{2}$-TPP and coated with PDA (AIBI@H$\mathrm{mMnO}_{2}$-TPP@PDA, AHTP), which could pervert the premature leakage of AIBI due to the excellent stability of PDA shell at $\mathrm{pH}$ 7.4. In this study, we chose osteosarcoma (OS), the most common malignant solid tumor that affects bones [25], as a treatment model. Arginine-glycine-aspartate (RGD), a cell-affinitive peptide can interact with $\alpha v \beta 3$ and $\alpha v \beta 5$ integrin receptors, which are widely expressed in various cancer cells [26-28], including OS cell lines such as MNNG/HOS and MG-63 cells $[29,30]$. Therefore, RGD with specific tumor-targeting properties was finally conjugated onto AHTP to obtain

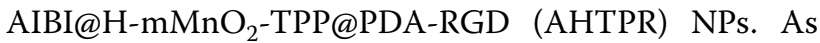
shown in Scheme 1b, surface modified RGD could promote AHTPR NPs specific targeting to OS cells. After the PDA shell was destroyed in the acidic tumor environment, the NPs could accumulate in mitochondria through the TPP targeting ability. With the irradiation of NIR light, the NPs could generate low temperature locally, which might subsequently stimulate the thermal decomposition of AIBI to induce free radicals burst. More importantly, the intracellular GSH could be oxidized into GSSG by $\mathrm{MnO}_{2}$, which significantly decreased the consumption of the alkyl radicals. Consequently, a large number of free radicals rapidly accumulated in mitochondria, decreased mitochondrial membrane potential, and ultimately provoked the mitochondriamediated cell apoptosis. Taken together, this work provided an innovative anticancer therapeutic strategy to achieve synergistically enhanced mitochondrial targeting LPTT/TDT.

\section{Methods \\ Materials}

Tetraethyl orthosilicate (TEOS), dopamine hydrochloride, anhydrous ethanol, ammonium hydroxide $\left(\mathrm{NH}_{3} \cdot \mathrm{H}_{2} \mathrm{O}\right), \quad \mathrm{N}$-hydroxysuccinimide (NHS), $\mathrm{N}$-(3-dimethylaminopropyl)-N-ethylcarbodiimide hydrochloride (EDC), and triphenylphosphine (TPP) were obtained from Sigma-Aldrich (St. Louis, MO, USA). Potassium permanganate $\left(\mathrm{KMnO}_{4}, 99 \%\right)$, and sodium carbonate $\left(\mathrm{Na}_{2} \mathrm{CO}_{3}\right)$, were obtained from Sinopharm Chemical Reagent Co., Ltd. (Shanghai, China). 2,2'-azobis[2-(2-imidazolin-2-yl) propane] dihydrochloride (AIBI) was purchased from Macklin Biochemical Co., Ltd. (Shanghai, China). Primary antibodies against Bcl-2 (Cat No. GTX100064), Bax (Cat No. GTX109683), Cytochrome c (Cyt-c, Cat No. GTX108585), cleavedCaspase-9 (Cat No. GTX22324), cleaved-Caspase-3 (Cat 


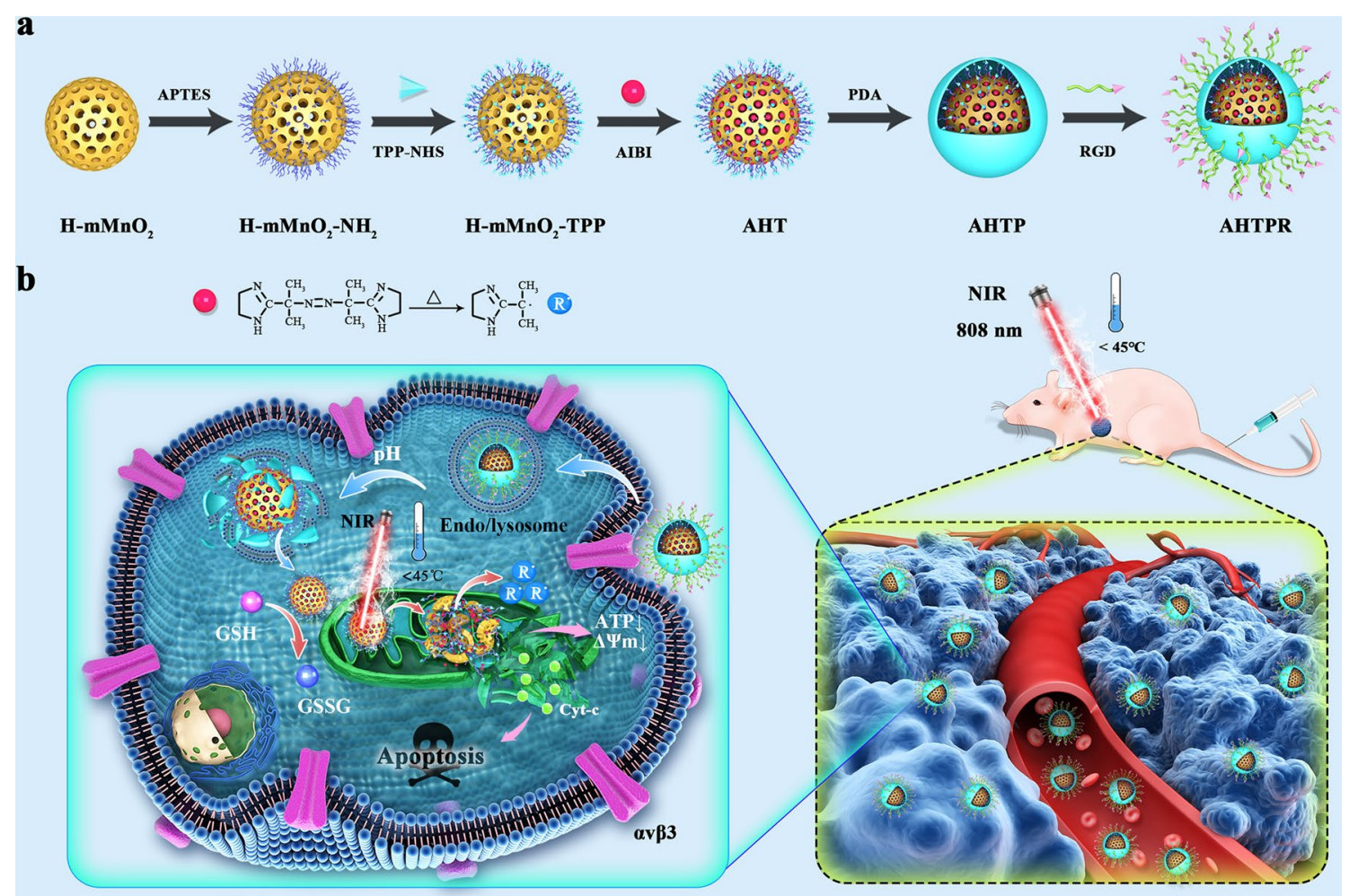

Scheme 1 a Schematic illustration of the synthesis procedures of AHTPR NPS. $\mathbf{b}$ The application of the NPs in the synergistic mitochondria-targeted LPTT/TDT

No. GTX22302) and GAPDH (Cat No. GTX100118) were purchased from GeneTex (Irvine, CA, USA). All other chemicals and reagents were of the highest quality commercially available and used as received.

\section{Synthesis of hollow mesoporous $\mathrm{MnO}_{2}\left(\mathrm{H}-\mathrm{mMnO}_{2}\right)$}

$\mathrm{H}-\mathrm{mMnO} 2 \mathrm{NPs}$ were synthesized as previously described with mild modification [31]. In brief, solid $\mathrm{SiO}_{2} \mathrm{NPs}$ $\left(\mathrm{sSiO}_{2}\right)$ were first synthesized according to the following route: $2 \mathrm{~mL}$ of TEOS was added dropwise to a mixed solution containing $12 \mathrm{~mL}$ of ethanol, $3 \mathrm{~mL}$ of deionized water, and $1 \mathrm{~mL} \mathrm{NH} \cdot \mathrm{H}_{2} \mathrm{O}$, and stirred at $50{ }^{\circ} \mathrm{C}$ for $2 \mathrm{~h}$. Subsequently, the $\mathrm{sSiO}_{2} \mathrm{NPs}$ were collected by centrifugation at 10,000 rpm for $10 \mathrm{~min}$, and then washed by ethanol and DI water three times, respectively.

For the synthesis of $\mathrm{sSiO}_{2} @ \mathrm{MnO}_{2} \mathrm{NPs}$, an aqueous solution of $\mathrm{KMnO}_{4}(500 \mathrm{mg})$ was dropwise added into the above $\mathrm{sSiO}_{2}$ aqueous suspension under ultrasonication. After stirring for $12 \mathrm{~h}$, the precipitate obtained by centrifugation at 10,000 rpm for $10 \mathrm{~min}$ and washed with DI water for three times. To etch the inner $\mathrm{SiO}_{2}$ template, the as-prepared $\mathrm{sSiO}_{2} @ \mathrm{MnO}_{2} \mathrm{NPs}$ was dispersed in a $\mathrm{Na}_{2} \mathrm{CO}_{3}$ aqueous solution and heated at $60{ }^{\circ} \mathrm{C}$ for $12 \mathrm{~h}$. Finally, the obtained hollow mesoporous $\mathrm{MnO}_{2}$
$\left(\mathrm{H}-\mathrm{mMnO}_{2}\right)$ products were collected by centrifugation and washed with DI water for three times.

\section{Synthesis of $\mathrm{H}-\mathrm{mMnO}_{2}$-TPP}

For the synthesis of the TPP modified $\mathrm{H}-\mathrm{mMnO}_{2}$ ( $\mathrm{H}-\mathrm{mMnO}_{2}$-TPP), the surface of $\mathrm{H}-\mathrm{mMnO}_{2}$ was first functionalized with amine groups. $75 \mathrm{mg} \mathrm{H}-\mathrm{mMnO}_{2}$ were dispersed in methylbenzene $(60 \mathrm{~mL})$ with the help of ultrasonication. Then, $250 \mu \mathrm{L}$ of APTES was added dropwise to the solution and heated to $80{ }^{\circ} \mathrm{C}$ in $\mathrm{N}_{2}$ environment and kept for $12 \mathrm{~h}$. After that, the obtained amino-functionalized $\mathrm{H}-\mathrm{mMnO}_{2} \quad\left(\mathrm{H}-\mathrm{mMnO}_{2}-\mathrm{NH}_{2}\right)$ were collected by centrifugation and washed several times with ethanol to remove the remaining solvent and rinsed by deionized water for three times.

To prepare $\mathrm{H}-\mathrm{mMnO}_{2}$-TPP, TPP-NHS was firstly synthesized following the previously reported method [32]. Then, $10 \mathrm{mg}$ TPP-NHS was dissolved under stirring in $10 \mathrm{~mL}$ of DMSO and then mixed with $10 \mathrm{mg}$ $\mathrm{H}-\mathrm{mMnO}_{2}$ under ultrasonication for $30 \mathrm{~min}$. Then, the mixture was stirred at room temperature for $24 \mathrm{~h}$. After centrifugation at $10,000 \mathrm{rpm}$ for $10 \mathrm{~min}$, the resulting $\mathrm{H}$ - $\mathrm{mMnO}_{2}$-TPP NPs were collected and washed with DI water for three times. 


\section{Preparation of AIBI@H-mMnO${ }_{2}$-TPP@PDA (AHTP)}

For AIBI loading, $5 \mathrm{~mL}$ as-synthesized $\mathrm{H}$-mMnO $\mathrm{m}_{2}$-TPP solution $\left(2 \mathrm{mg} \mathrm{mL}^{-1}\right)$ was dispersed in $20 \mathrm{~mL}$ AIBI aqueous solution $\left(2 \mathrm{mg} \mathrm{mL}^{-1}\right)$ and stirred overnight at room temperature in darkness. The solution was then centrifuged at 12,000 rpm for $10 \mathrm{~min}$ and washed three times DI with water to remove the remaining AIBI. The resulting products $\left(\mathrm{AIBI} @ \mathrm{H}-\mathrm{mMnO}_{2}-\mathrm{TPP}, \mathrm{AHT}\right)$ were dispersed in $5 \mathrm{~mL}$ water for further use.

The obtained AHT NPs were dispersed in $10 \mathrm{~mL}$ Tris$\mathrm{HCl}$ buffer $(\mathrm{pH}=8.5,10 \mathrm{mM})$ containing dopamine hydrochloride $(10 \mathrm{mg})$ and stirred at room temperature for $6 \mathrm{~h}$. Afterwards, the prepared PDA-coated NPs

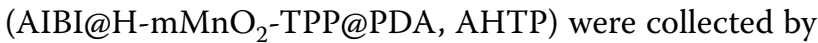
centrifugation and washed with DI water for three times.

\section{Synthesis of AIBI@H-mMnO 2 -TPP@PDA-RGD (AHTPR)}

Briefly, $5 \mathrm{mg}$ RGD was dispersed in DMSO $(2 \mathrm{~mL})$ and then mixed with $2 \mathrm{~mL}$ AHTP solution $\left(2 \mathrm{mg} \mathrm{mL}^{-1}\right)$, which was stirred overnight at room temperature in the dark. Thereafter, the resultants were rinsed in DI water three times by centrifugation $(10,000 \mathrm{rpm})$. Finally, the obtained purified AIBI@H-mMnO $2-T P P @ P D A-R G D$ (AHTPR) NPs were stored in the dark for further characterization and application.

\section{Characterizations}

Scanning electron microscope (SEM) images were taken on a transmission electron microscope (ZEISS Gemini 300). Transmission electron microscopy (TEM) images were recorded on a JEOL JEM F200 electron microscope operating at $200 \mathrm{kV}$. Dynamic light scattering (DLS) and zeta potential were evaluated by using a Zetasizer Nano ZS90 equipment (Malvern Instruments, UK). Fourier transform infrared (FTIR) spectra were scanned on a Thermo Nicolet iS50 FTIR spectrometer in the range of $400-4000 \mathrm{~cm}^{-1}$. UV-vis absorption spectra was evaluated with a spectrophotometer (UV-3600 Shimadzu, Japan). The X-ray photoelectronic spectroscopy (XPS) spectra were recorded with a spectrophotometer (Thermo Scientific K-Alpha). The Brunauer-EmmettTeller (BET) approach (ASAP 2460, Micromeritics, USA) was used to investigate the surface area and pore size distributions of the samples. Electron paramagnetic resonance (EPR) spectroscopy spectrums were obtained from a Bruker EMXnano Spectrometer.

\section{In vitro photothermal performance}

To determine the photothermal performance of AHTPR NPs in vitro, the temperature variation was monitored in real-time and recorded at the designed time intervals using an infrared thermal imaging camera (Testo 865, Testo, Schwarzwald, Germany). To investigate the concentration and time-dependency of the photothermal effect, various concentrations of AHTPR NPs in PBS (0, 30,60 , and $120 \mu \mathrm{g} \mathrm{mL}^{-1}$ ) were irradiated with an $808 \mathrm{~nm}$ laser $\left(1.0 \mathrm{~W} \mathrm{~cm}^{-2}\right)$ for $10 \mathrm{~min}$. To further examine the laser power density-dependency of the photothermal effect, $60 \mathrm{ug} \mathrm{mL} \mathrm{m}^{-1}$ samples were irradiated at different power densities $\left(0.5,1.0,1.5\right.$, and $\left.2.0 \mathrm{~W} \mathrm{~cm}^{-2}\right)$ for $10 \mathrm{~min}$. In addition, the photothermal stability of AHTPR NPs were study by five cycles of ON/OFF NIR-laser irradiation. In brief, the samples were irradiated for $10 \mathrm{~min}$, and then cooled down to room temperature prior to the next cycle.

\section{Hemolysis assay}

Briefly, $1 \mathrm{~mL}$ anticoagulated whole blood samples were obtained from the orbital venous plexus of health Kunming mice and then centrifuged at $8000 \mathrm{~g}$ at $4{ }^{\circ} \mathrm{C}$ for 5 min to isolate red blood cells (RBCs). Afterward, RBCs were washed five times and diluted with $2 \mathrm{~mL}$ PBS. RBC diluted suspensions $(200 \mu \mathrm{L})$ were added into 800 $\mu \mathrm{L}$ of deionized water (positive control), PBS (negative control), or various concentration of AHTPR NPs (50$\left.1600 \mu \mathrm{g} \mathrm{mL}^{-1}\right)$. After $2 \mathrm{~h}$ incubation at $37^{\circ} \mathrm{C}$ in a shaker table, the mixtures were centrifuged at $8000 \mathrm{~g}$ at $4{ }^{\circ} \mathrm{C}$ for 5 min. Subsequently, the absorbance of all gained supernatant was measured at $541 \mathrm{~nm}$. In the end, the RBCs' hemolysis percentage was calculated by using the following equation: Hemolysis percentages $(\%)=\left(I_{\text {sample }}\right.$ $-I$ negative control $) /\left(I_{\text {positive control }}-I_{\text {negative control }}\right) \times 100 \%$, where $I$ sample, $I$ negative control, $I$ positive control, and $I$ negative control represent the absorbance of the sample, negative control, and positive control, respectively.

\section{Drug release in vitro}

The dialysis method was utilized to analyze the triggered release behavior of AIBI from AHTPR NPs in different environments. Briefly, $1 \mathrm{~mL}$ AHTPR $(2 \mathrm{mg} / \mathrm{mL})$ NPs was dialyzed against PBS $(30 \mathrm{~mL})$ at different $\mathrm{pH}$ values $(5.0$ and 7.4) with or without exposure to NIR laser irradiation $\left(1.0 \mathrm{~W} \mathrm{~cm}{ }^{-2}\right)$ for $10 \mathrm{~min}$ at $37{ }^{\circ} \mathrm{C}$ in a shaking bath. At the specified time points, the amount of released AIBI was determined by UV-vis spectroscopy.

\section{Cell culture}

Human OS cells (MNNG/HOS) were purchased from Cell Bank of Shanghai Institute of Biochemistry and Cell Biology, Chinese Academy of Sciences. Bone marrow stromal cells (BMSCs) were kindly provided by Dr. Song Gong (Tongji Medical College, Huazhong University of Science and Technology). The OS cells were maintained in $\alpha$-modified essential medium (MEM) (Hyclone) supplemented with 10\% fetal bovine serum (FBS) (Gibco; Thermo Fisher Scientific), and 1\% 
penicillin-streptomycin. BMSCs were cultured with Dulbecco's MEM (DMEM)/ F12 containing 15\% FBS and 1\% penicillin-streptomycin. All the cells were cultured at $37^{\circ} \mathrm{C}$ under an atmosphere of $5 \% \mathrm{CO} 2$.

\section{Cellular uptake}

To investigate the cellular uptake efficiency of the NPs, MNNG/HOS cells $\left(1 \times 10^{5}\right.$ per well $)$ were seeded and cultured in six-well plates at $37^{\circ} \mathrm{C}$ in a humidified atmosphere of $5 \% \mathrm{CO} 2$ for $24 \mathrm{~h}$. After complete adhesion, the cells were incubated with free ICG and ICG-labeled NPs (ICG@HTP or ICG@HTPR) at an equivalent ICG concentration $\left(15 \mu \mathrm{g} \mathrm{mL}^{-1}\right)$ for $4 \mathrm{~h}$, respectively. For competitive experiment, cells were pretreated with free RGD (2 mg mL $\mathrm{mL}^{-1}$ ) for $2 \mathrm{~h}$, and then incubated with ICG@ HTPR NPs for $4 \mathrm{~h}$. Subsequently, the cells were stained with Hoechst $33,342\left(10 \mu \mathrm{g} \mathrm{mL}{ }^{-1}\right)$ for $10 \mathrm{~min}$. After washing with PBS for three times, the cells were imaged by a fluorescence microscope (Olympus Corporation, Tokyo, Japan).

In order to systematically investigate the mechanism of cellular uptake, we then used the MNNG/HOS cells to incubate with ICG@HTPR NPs under different conditions. The seeded MNNG/HOS cells were pre-treated with the clathrin pathway inhibitor chlorpromazine $(100 \mu \mathrm{M})$, caveolae inhibitor genistein $(200 \mu \mathrm{M})$, micropinocytosis inhibitor amiloride $(50 \mu \mathrm{M})$, and phagocytosis inhibitor cytochalasin $\mathrm{D}(20 \mu \mathrm{M}))$ at $37^{\circ} \mathrm{C}$ for $1 \mathrm{~h}$ and then incubated with ICG@HTPR NPs at $37{ }^{\circ} \mathrm{C}$ for 4 h. Cells treated with ICG@HTPR NPs at $37{ }^{\circ} \mathrm{C}$ served as the control group. Subsequently, the cells were carefully washed three times with cold PBS and harvested for flow cytometry to determine the fluorescence intensity. Furthermore, internalization assays were also performed at low temperature $\left(4{ }^{\circ} \mathrm{C}\right)$ in the absence of endocytic inhibitors to reflect the energy-dependent endocytosis pathway.

\section{Mitochondria targeting property}

To trace the intracellular localization of AHTPR NPs, MNNG-HOS cells were seed in six-well plates at a density of $1 \times 10^{5}$ per well and incubated for 24 . Then the cells were treated with ICG labeled NPs (ICG@HPR and ICG@HTPR) at an equivalent ICG concentration $\left(15 \mu \mathrm{g} \mathrm{mL}^{-1}\right)$ for $6 \mathrm{~h}$. Then, the cells were stained with Mito-Tracker Green (Beyotime Biotechnology, China) for according to the manufacturer's instruction. Afterwards, the cell nuclei were stained with Hoechst 33,342 $\left(10 \mu \mathrm{g} \mathrm{mL}^{-1}\right)$ for $10 \mathrm{~min}$. After washing with PBS for three times, the mitochondrial co-localization imaging was observed by a fluorescence microscope.

\section{Intracellular free radical detection}

Intracellular generation of free radicals was investigated by a DCFH-DA fluorescent probe. Briefly, MNNG/HOS cells were seed in a six-well plate at a density of $5 \times 10^{4} /$ well. After $24 \mathrm{~h}$ incubation at $37^{\circ} \mathrm{C}, \mathrm{PBS}$, AIBI, HTPR and AHTPR were added. After $4 \mathrm{~h}$ incubation for intracellular uptake, the cells were irradiated with $808 \mathrm{~nm}$ NIR light at a power density of $1.0 \mathrm{~W} \mathrm{~cm}^{-2}$ for $10 \mathrm{~min}$ and incubated for another $4 \mathrm{~h}$. After that, the culture media were discarded and the ROS probe DCF-DA in DMEM $(10 \mu \mathrm{M})$ were added and incubated for another $45 \mathrm{~min}$. Subsequently, the DMEM media were discarded and followed by PBS rinsing, then observed with a fluorescence microscopy.

\section{Cell viability assay}

The cell viability was determined by using the Cell counting kit-8 (CCK-8) assay. In brief, MNNG/HOS cells (5000 cells per well) were seeded into 96 well plates and cultured for $24 \mathrm{~h}$ to allow cell attachment. After the corresponding treatment, the cells were cultured for another $24 \mathrm{~h}$ at $37^{\circ} \mathrm{C}$. Afterwards, the supernatant was discarded and washed twice carefully with PBS. Then, $100 \mu \mathrm{L}$ fresh medium containing $10 \%$ CCK- 8 solution were added. After incubation in dark for $2 \mathrm{~h}$, the cell viability was assessed by measuring sample absorbance at $450 \mathrm{~nm}$ by a microplate reader (Biotek, Winooski, VT, USA).

\section{Live/dead cells staining}

The live/dead cell staining assay was utilized to intuitively evaluate the cell apoptosis-inducing activity of different formulations in MNNG/HOS cells. Briefly, cells were seeded in 96-well plates at a density of 5000 cells per well. After $24 \mathrm{~h}$ of incubation, the cells were treated according to the description aforementioned for another $24 \mathrm{~h}$. Afterwards, the cells were stained with $2 \mu \mathrm{M}$ Calcein$\mathrm{AM}$ and $2 \mu \mathrm{M}$ propidium iodide (PI) for $15 \mathrm{~min}$. Following staining, cells were washed twice with PBS and observed by using a fluorescence microscopy.

\section{Cell apoptosis}

MNNG/HOS cells were seeded in six-well plates at a density of $1 \times 10^{5}$ per well. After incubation at $37^{\circ} \mathrm{C}$ for $24 \mathrm{~h}$, the cells were treated according to the description aforementioned. Afterwards, the cell apoptosis was assessed by flow cytometry (Becton Dickinson, Franklin Lakes, New Jersey, USA) after cells were stained with Annexin V- fluorescein isothiocyanate (FITC) / propidium iodide (PI) dual staining (Nanjing Keygen Biotech, Nanjing, China) according to the manufacturer's protocol. 


\section{Assessment of intracellular GSH}

The intracellular GSH was detected using Ellman's reagents. In Brief, MNNG/HOS cells were incubated with different materials and treated accordingly. Then the treated cells were collected by repeated cycle of freezing and thawing and then centrifuged to collect the supernatants for the measurement of GSH based on the standard protocol.

\section{Analysis of mitochondrial membrane potential (MMP) and intracellular ATP levels}

The change of mitochondrial membrane potential was determined by $5,5^{\prime}, 6,6^{\prime}$-tetrachloro- $1,1^{\prime}, 3,3^{\prime}$ tetraethylbenzimidazolocarbocyanine iodide (JC-1) detection Kit. MNNG/HOS cells were seeded in sixwell plates and cultured for $24 \mathrm{~h}$. After incubation with PBS, AIBI, AHPR and AHTPR NPs for $6 \mathrm{~h}$, the cells were exposed to an NIR laser $\left(808 \mathrm{~nm}, 1.0 \mathrm{~W} \mathrm{~cm}^{-2}\right)$ for $10 \mathrm{~min}$. Afterwards, the cells were stained by JC-1 $\left(5 \mu \mathrm{g} \mathrm{mL}^{-1}\right)$ for $20 \mathrm{~min}$. After washing with PBS, the cells were imaged by fluorescence microscopy.

The intracellular adenosine triphosphate (ATP) levels were detected by ATP determination kit (Beyotime, China). Briefly, the cells were collected and lysed with lysis buffer after the corresponding treatment for $24 \mathrm{~h}$. After centrifugation at $12,000 \mathrm{rpm}$ at $4{ }^{\circ} \mathrm{C}$ for $5 \mathrm{~min}$, the supernatant was harvested for subsequent determination. The ATP concentration of the samples was determined by a standard curve which was generated according to the manufacturer's protocol.

\section{Western blotting analysis}

After different treatments, the MNNG/HOS cells were lysed by RIPA buffer (Thermo Fisher Scientific) containing protease inhibitors and phosphatase inhibitors and the concentration of protein was determined via the BCA Protein Assay kit (Beyotime Biotechnology Co. Ltd). Subsequently, the same protein concentrations of various samples were separated by $12 \%$ of sodium dodecyl-polyacrylamide gel electrophoresis (SDS-PAGE) and blotted on polyvinylidene difluoride (PVDF) membranes. After being blocked by $5 \%$ non-fat milk for $1 \mathrm{~h}$, the PVDF membranes were incubated with primary antibody overnight at $4{ }^{\circ} \mathrm{C}$. Then the PVDF membranes were washed with TBST for three times and incubated with the secondary antibody for $1 \mathrm{~h}$ at room temperature. Afterwards, the membranes were washed three times with TBST buffer and detected by using electrochemiluminescence detection reagent (EMD Millipore) according to the manufacturer's instructions.

\section{Animal models}

Female BALB/c nude mice (4-6 weeks) were purchased from Beijing HFK Bioscience Co. Ltd. All animal experiments were performed according to protocols approved by the Institutional Animal Care and Use Committee (IACUC) at Tongji Medical College, Huazhong University of Science and Technology (IACUC Number: S2503).

To establish tumor models, MNNG/HOS cells $\left(1 \times 10^{7}\right)$ suspended in $200 \mu \mathrm{L}$ cold PBS were subcutaneously injected into the right flank of nude mice. The tumor-bearing mice were treated when the tumor volume reached around $100 \mathrm{~mm}^{3}$. The tumor volume was calculated using the formula: Tumor volume $=1 / 2 \times$ length $\times(\text { width })^{2}$. Where the length and width determined by vernier caliper are the longest and shortest dimension of the tumor, respectively.

\section{In vivo fluorescence imaging and photothermal imaging}

For vivo tumor fluorescence imaging, and $200 \mu \mathrm{L}$ of ICG labeled NPs (ICG@HTP and ICG@HTPR, 2 mg mL ${ }^{-1}$ ) was injected into the tumor-bearing mice via tail vein. The mice $(n=3)$ were anesthetized and image using IVIS small animal imaging system (PerkinElmer Inc., Waltham, USA $)$ at the appointed time points $(0 \mathrm{~h}, 1 \mathrm{~h}$, $3 \mathrm{~h}, 6 \mathrm{~h}, 12 \mathrm{~h}$ and $24 \mathrm{~h}$ ). After injection for $24 \mathrm{~h}$, the mice were sacrificed, and the tumors and main organs (heart, lung, liver, spleen, and kidney) were harvested for ex vivo imaging.

Photothermal imaging was performed following a similar procedure. Briefly, $200 \mu \mathrm{L}$ PBS or NPs (AHTP and AHTPR, $2 \mathrm{mg} \mathrm{mL}^{-1}$ ) were intravenously injected into MNNG/HOS tumor-bearing mice $(n=3)$, respectively. The tumor regions of the mice were irradiated with an $808 \mathrm{~nm}$ laser $\left(1.0 \mathrm{~W} \mathrm{~cm}^{-2}\right)$ continuously for $5 \mathrm{~min}$ after $6 \mathrm{~h}$ post-injection. The changes in temperature in the tumor region were measured by infrared thermal imaging camera (Testo 865, Testo, Schwarzwald, Germany) every minute.

\section{In vivo synergistic cancer therapy and biosafety}

When the volume of tumors reached approximately $100 \mathrm{~mm}^{3}$, the MNNG/HOS tumor-bearing mice were randomly assigned to five groups $(\mathrm{n}=5)$ : (1) control group, (2) NIR, (3) AIBI + NIR, (4) AHTP + NIR, and (5) AHTPR + NIR. The mice without any treatment served as control group. $200 \mu \mathrm{L}$ of different materials $\left(10 \mathrm{mg} \mathrm{kg}^{-1}\right)$ were injected into the tail vein of tumor-bearing mice every $2 \mathrm{~d}$. At $6 \mathrm{~h}$ post-injection, the tumor site was treated with $808 \mathrm{~nm}$ NIR laser irradiation $\left(1.0 \mathrm{~W} \mathrm{~cm}{ }^{-2}\right.$, $5 \mathrm{~min}$ ). The tumor volume and body weight were monitored every other day during the therapy. All mice were sacrificed after the therapy for two weeks, the tumors 
were extracted, weighed and photographed. Thereafter, the tumor tissues were collected and examined by hematoxylin and eosin (H\&E) staining, Ki-67 and terminal deoxynucleotidyl transferase-mediated dUTP nick end labeling (TUNEL) assay. To assess the in vivo biosafety of the treatments, major organs (heart, liver, spleen, lung, and kidney) were extracted for H\&E staining assay. Furthermore, the blood of the mice was extracted to perform the hematology analysis.

\section{Statistical analysis}

All the experiments were performed three times and the data were presented as mean \pm standard deviation (SD). The statistical significance was determined by Student's t-test and one-way analysis of variance (ANOVA) by using GraphPad Prism version 7.00. $\mathrm{P}<0.05$ was considered as statistically significant.

\section{Results and discussion}

Preparation and characterization of the AIBI@H-mMnO $\mathrm{O}_{2}$-TPP@PDA-RGD (AHTPR)

The procedure for the synthesis of the NPs was illustrated in Scheme 1. In brief, $\mathrm{H}-\mathrm{mMnO}_{2} \mathrm{NPs}$ were first fabricated according to a previously reported protocol with slight modifications [23]. For the preparation of TPP modified $\mathrm{H}-\mathrm{mMnO}_{2}\left(\mathrm{H}-\mathrm{mMnO}_{2}-\mathrm{TPP}\right)$, the surface of $\mathrm{H}-\mathrm{mMnO}_{2}$ was functionalized with amine groups. Subsequently, AIBI was loaded into $\mathrm{H}-\mathrm{mMnO}_{2}-$ TPP NPs to obtain AIBI@H-mMnO $\mathrm{M}_{2}$-TPP (AHT). PDA was then coated on the surface of AHT as gatekeepers to prevent the premature leakage of cargo to obtain AIBI@H-mMnO2-TPP@PDA (AHTP). Finally, the active-targeting ligand RGD was conjugated to the PDA coating through Michael addition reaction a

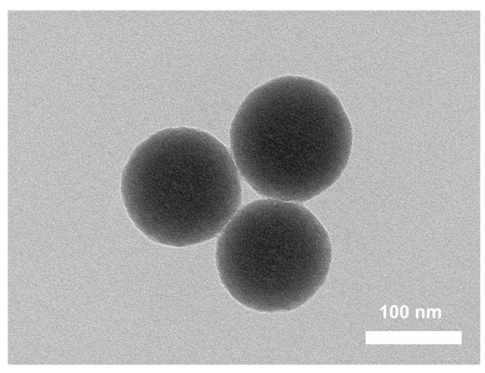

d
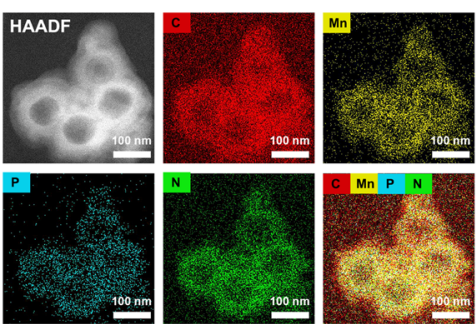

f

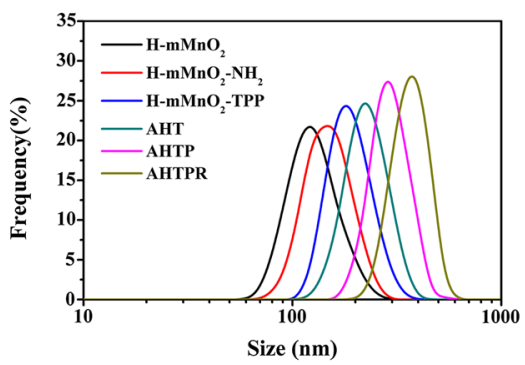

b

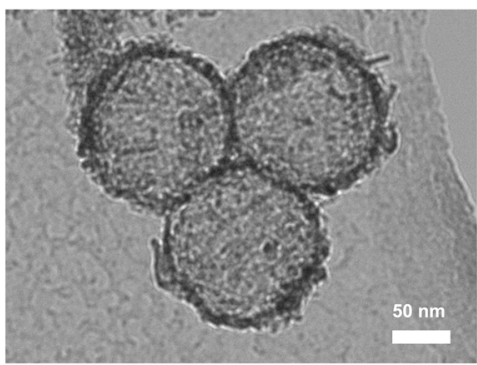

C

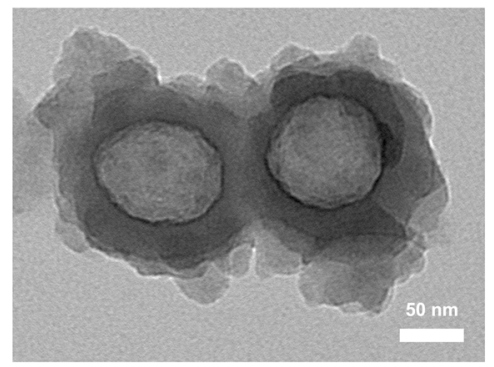

e
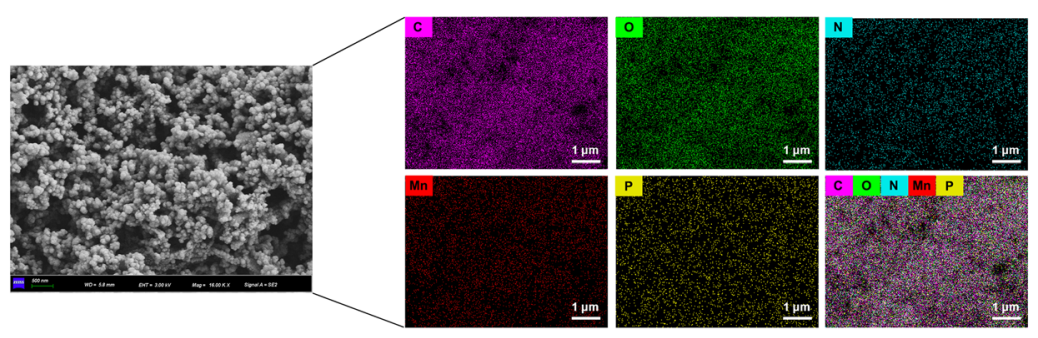

g

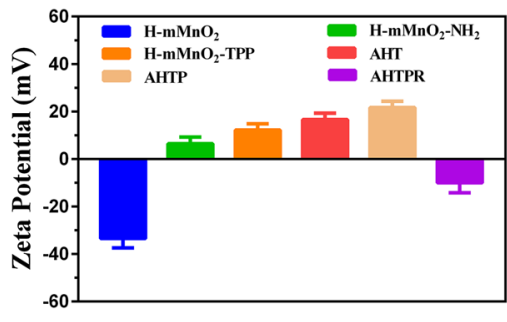

Fig. 1 The characterization analysis of the synthesized formulations. TEM images of $\mathbf{a} s \mathrm{SiO}_{2}$, b sSiO,@MnO, and $\mathbf{c}$ AHTPR. d, e TEM mapping and SEM mapping of the AHTPR NPs. fThe DLS size and $\mathbf{g}$ Zeta potential, and $\mathbf{h}$ FTIR spectra of $\mathrm{H}-\mathrm{mMnO}_{2}, \mathrm{H}-\mathrm{mMnO}_{2}-\mathrm{NH}_{2}, \mathrm{H}-\mathrm{mMnO}_{2}-\mathrm{TPP}, \mathrm{HTP}, \mathrm{AHTP}$, and AHTPR 
[33], resulting in AIBI@H-mMnO${ }_{2}$-TPP@PDA-RGD (AHTPR).

The morphology and size of the NPs were characterized by a TEM. As depicted in Fig. 1a and Additional file 1: Fig. S1, the as-prepare $\mathrm{sSiO}_{2} \mathrm{NPs}$ displayed uniform sphere-like morphology and the average size was approximately $120.5 \mathrm{~nm}$ as determined by TEM. Obviously, the TEM image of $\mathrm{H}-\mathrm{MnO}_{2}$ informed the hollow mesoporous structure (Fig. 1b). Furthermore, the Brunauer-Emmett-Teller (BET) approach was used to investigate the surface area and pore size distributions of the samples. As shown in Additional file 1: Fig. $\mathrm{S} 2$ the BET specific surface area of the $\mathrm{H}-\mathrm{mMnO}_{2}$-TPP NPs was determined to be $285.65 \mathrm{~m}^{2} \mathrm{~g}^{-1}$ with the average pore size distribution at around $3.39 \mathrm{~nm}$. These results informed that the as-prepared $\mathrm{H}-\mathrm{mMnO} 2 \mathrm{NPs}$ possessed potential as ideal nanocarrier for delivering therapeutic agents. As revealed in Fig. 1c, the obtained AHTPR NPs obviously revealed a distinct two-layer structure. Further, the TEM mapping confirmed the core-shell structure of the AHTPR NPs (Fig. 1d). Additionally, SEM mapping (Fig. 1e) and the corresponding energy-dispersive X-ray spectroscopy (EDS) (Additional file 1: Fig. S3) indicated the coexistence of $\mathrm{C}, \mathrm{N}, \mathrm{O}, \mathrm{Mn}$, and $\mathrm{P}$ elements. The size distribution of the NPs was measured by DLS analysis. As displayed in Fig. 1f, the hydrodynamic diameters of $\mathrm{H}-\mathrm{mMnO}_{2}, \mathrm{H}-\mathrm{mMnO}_{2}-\mathrm{NH}_{2}, \mathrm{H}-\mathrm{mMnO}_{2}$-TPP, AHT, AHTP, and AHTPR NPs were about $128.8 \mathrm{~nm}, 151.0 \mathrm{~nm}$, and $191.3 \mathrm{~nm}, 229.4 \mathrm{~nm}, 295.6 \mathrm{~nm}$, and $370.0 \mathrm{~nm}$ respectively. Notably, the size measured by DLS was larger than the result obtained from TEM images, which might be ascribed to the hydration of NPs in water [12].

The dispersity of the final samples (AHTPR NPs) was monitored in different media (water, $\alpha$-MEM culture medium with or without $10 \%$ FBS) over a prolonged incubation time up to 7 days. As shown in Additional file 1: Fig. S4a, AHTPR NPs could be well dispersed in water, $\alpha$-MEM culture medium with or without $10 \%$ FBS with no obvious agglomeration or precipitation after being stored for one week, which is conducive to prolonging blood circulation time in vivo for use. Subsequently, the colloidal stability of AHTPR NPs was determined by characterizing the hydrodynamic diameters. As depicted in Additional file 1: Fig. S4b, noticeable changes were found in hydrodynamic diameters of the as-prepared AHTPR NPs during $7 \mathrm{~d}$ of incubation in water, $\alpha$-MEM culture medium with or without $10 \%$ FBS, illustrating their remarkable long-term stability in physiological solution, which makes possible for their prolonged circulation in vivo.

The zeta potential changes during the modification process were monitored. As shown in Fig. $2 \mathrm{~g}$, the zeta potentials of the $\mathrm{H}-\mathrm{mMnO}_{2}, \mathrm{H}-\mathrm{mMnO}_{2}-\mathrm{NH}_{2}$,
H- $\mathrm{mMnO}_{2}$-TPP, AHT, AHTP, and AHTPR NPs were $-33.45 \pm 4.01 \mathrm{mv}, 6.42 \pm 2.78 \mathrm{mv}, 12.16 \pm 2.69 \mathrm{mv}$, $16.60 \pm 2.74 \mathrm{mv}, 21.68 \pm 2.66 \mathrm{mv}$, and $-9.97 \pm 4.27 \mathrm{mv}$, respectively. These step-wise altered zeta potentials indicated the successful construction of the nano-system. Furthermore, FTIR spectroscopy was performed to validate the surface chemistry changes along the modification process. As revealed in Fig. $1 \mathrm{~h}$, the bending vibration of $-\mathrm{NH}_{2}$ at $1514 \mathrm{~cm}^{-1}$ confirmed the successful modification of amino group on $\mathrm{H}-\mathrm{mMnO}_{2}$. Compared with the spectra of $\mathrm{H}-\mathrm{mMnO}_{2}-\mathrm{NH}_{2}$, a new peak at $1118 \mathrm{~cm}^{-1}$ was observed in $\mathrm{H}-\mathrm{mMnO}_{2}$-TPP, which was consistent with the C-N stretching of amide groups [34]. After loading AIBI, the AHT NPs demonstrated two characteristic peaks, such as the $-\mathrm{CH}_{3}$ stretching vibration peak at $2921 \mathrm{~cm}^{-1}$ and the $\mathrm{N}=\mathrm{N}$ stretching vibration peak at $1572 \mathrm{~cm}^{-1}$, which confirmed the AIBI were successfully loaded into the AHT NPs. In comparison with AHT, the peaks at $1518 \mathrm{~cm}^{-1}$ in the spectrum of AHTP might be were ascribed to the aromatic $\mathrm{C}=\mathrm{C}$ stretching vibration of indole or indoline structures [35], which indicated the PDA-coating was successfully conjugated on the surface of the AHT NPs. Furthermore, the emergence of absorbance peaks at $1362 \mathrm{~cm}^{-1}$ and $957 \mathrm{~cm}^{-1}$ in the spectrum of AHTPR, ascribing to glycine $\left(-\mathrm{CH}_{2} \mathrm{C}=\mathrm{O}\right)$ and aspartic acid $(\mathrm{COOH})$ of the RGD peptide, respectively [36]. Based on these characterization results, we concluded that the AHTPR NPs were successfully synthesized.

\section{Photothermal properties of NPs}

To explore the photothermal performance of the assynthesized AHTPR NPs, the temperature changes of different preparations after exposure to NIR irradiation $(808 \mathrm{~nm})$ were recorded by an infrared thermal imaging camera. As exhibited in Additional file 1: Fig. S5, in comparison with other formulations (PBS and $\mathrm{H}-\mathrm{mMnO}_{2}$ ), the temperature of HTPR (at equal $\mathrm{H}-\mathrm{mMnO}_{2}$ concentration, $120 \mu \mathrm{g} \mathrm{mL}^{-1}$ ) NPs exhibited prominent photothermal conversion efficiency under the same condition, which might be contributed to the combination of two excellent photothermal agents (PDA and $\mathrm{H}-\mathrm{mMnO}_{2}$ ) [23]. Subsequently, the photothermal-conversion performance of AHTPR NPs at various concentrations under NIR laser irradiation $\left(1.0 \mathrm{~W} \mathrm{~cm}^{-2}, 10 \mathrm{~min}\right)$ was investigated. As shown in Fig. 2a and b, the temperature of AHTPR NPs exhibited an obvious concentration- and time-dependent rise. In marked contrast, the temperature of PBS rose slightly under the same conditions. Furthermore, it could be found that the photothermal efficiency of the AHTPR NPs displayed a promising laser power intensity-dependent manner (Fig. 2c). To validate the photothermal stability of the NPs, AHTPR NPs were challenged with five times heating-cooling cycles. 
$\mathbf{a}$

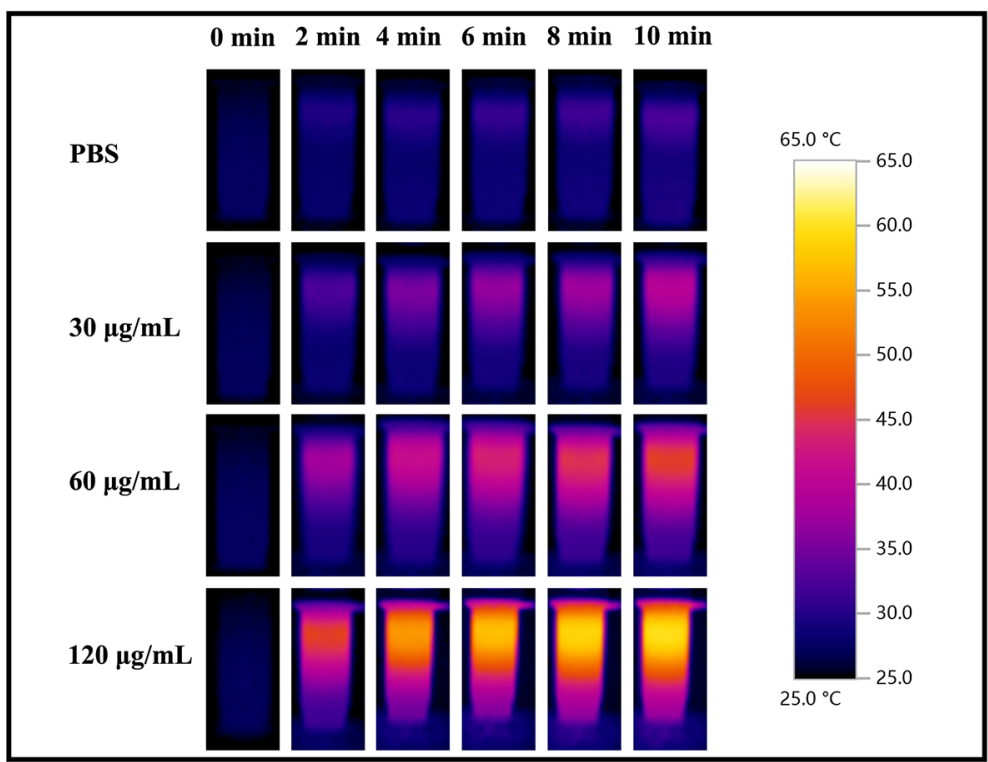

d

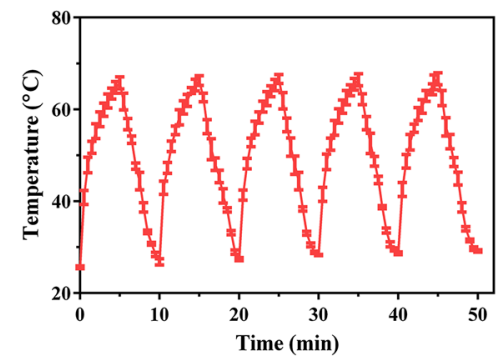

g

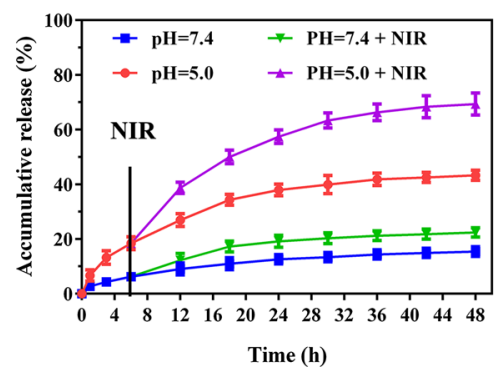

e

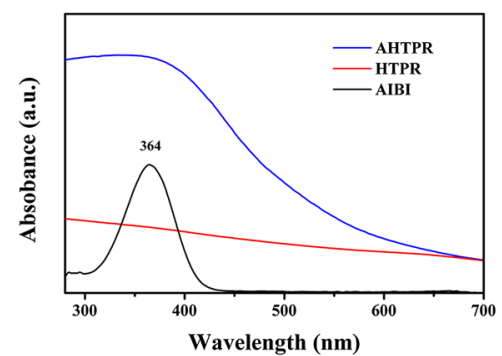

h

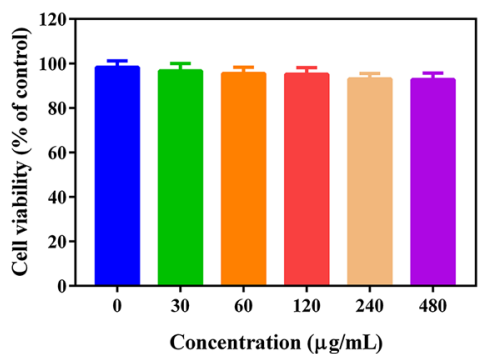

b

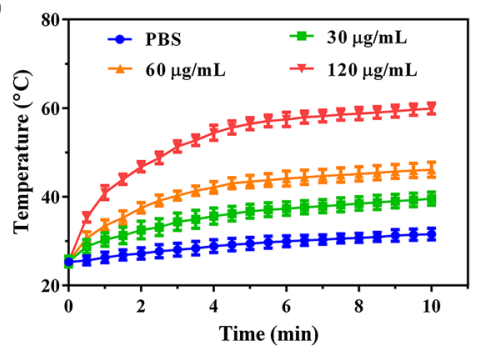

c

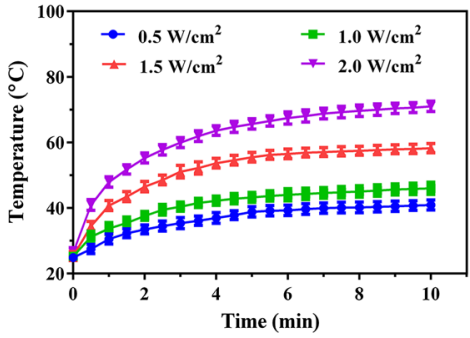

f

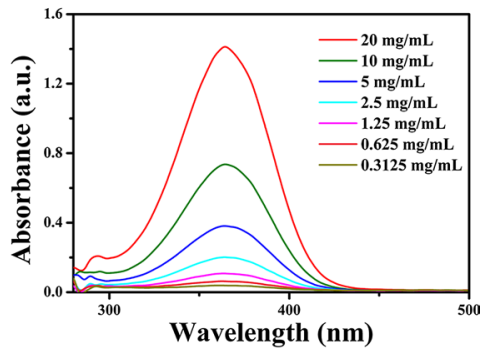

i

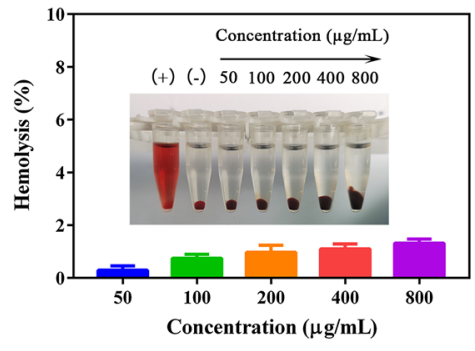

Fig. 2 Photothermal properties, release profiles and biocompatibility of AHTPR NPs in vitro. $\mathbf{a}$, $\mathbf{b}$ The infrared thermal images and time-dependent temperature elevation of AHTPR at various concentrations under $1.0 \mathrm{~W} \mathrm{~cm}^{-2} 808 \mathrm{~nm}$ laser irradiation. c Time-dependent temperature change of AHTPR (120 $\left.\mu \mathrm{g} \mathrm{mL}^{-1}\right)$ under $808 \mathrm{~nm}$ laser irradiation with different laser power. d Photothermal stability curve of AHTPR $\left(120 \mu \mathrm{g} \mathrm{mL} L^{-1}\right) \mathrm{NPs}$ following on/off NIR laser irradiation $\left(2.0 \mathrm{~W} \mathrm{~cm}^{-2}\right)$ for 5 cycles. e UV-vis spectra of AIBI, HTPR and AHTPR. fThe UV-vis absorption spectra of AIBI with different concentrations. $\mathbf{g}$ The release profiles of AIBI from AHTPR in PBS with different $\mathrm{pH}$ values without or with NIR irradiation (808 nm, $\left.1.0 \mathrm{~W} \mathrm{~cm}^{-2}, 10 \mathrm{~min}\right) \cdot \mathbf{h}$ Cell viability of BMSCs after $24 \mathrm{~h}$ of treatments with various concentrations of AHTPR NPs. $\mathbf{i}$ Hemolysis assay of different concentrations of AHTPR samples

As displayed in Fig. 2d, no obvious change was found in the temperature variation curves after laser irradiation for five cycles. The photothermal conversion efficiency of the NPs was calculated according to the previous method [37, 38]. According to the temperature change plot curve before and after irradiation (Additional file 1: Fig. S6a, b), the photothermal conversion efficiency ( $\eta$ ) of the AHTPR NPs was calculated by the formula as $37.61 \%$. Collectively, the prepared AHTPR NPs exhibited prominent photothermal conversion ability and outstanding 
photothermal stability, demonstrating their remarkable potential application value as efficient thermal agents for anticancer therapy.

\section{Drug loading and release}

In order to prevent premature drug leakage during circulation in the blood, HTPR was employed as a controlled drug delivery carrier for AIBI. As shown in Fig. 2e, AHTPR exhibited the characteristic absorbance peaks of AIBI at $364 \mathrm{~nm}$ as expected, indicating that AIBI was successfully loaded into HTPR. According to the absorption intensity of different concentrations of AIBI at $364 \mathrm{~nm}$ (Fig. 2f), the standard curve of AIBI was established (Additional file 1: Fig. S7). Subsequently, the loading efficiency of AIBI was calculated to be around $52.36 \pm 3.13 \%$ and the corresponding encapsulation efficiency was about $27.63 \pm 3.54 \%$.

To investigate the gating effect of the PDA shell for controlled release of AIBI, the release behavior of the NPs under different $\mathrm{pH}$ conditions was first evaluated. As shown in Fig. 2g, only slow release of AIBI (15.4\%) from NPs was observed at PH 7.4. Nevertheless, the amount of released AIBI increased up to $43.3 \%$ at pH 5.5 within the same incubation time of $48 \mathrm{~h}$, suggesting that the AIBI release from the NPs was significantly $\mathrm{pH}$-dependent. That might be attributed to the depolymerization of PDA shell in the acidic environment. The bare release of agents at neutral physiological environment indicated AHTPR could keep safe for normal tissue. Subsequently, the NIR-triggered release behavior of the NPs at PH 5.0 or 7.4 was evaluated under $808 \mathrm{~nm}$ laser irradiation. As illustrated in Fig. 2g, the AIBI release was dramatically increased at $\mathrm{pH} 5.0$ after NIR irradiation $\left(1.0 \mathrm{~W} \mathrm{~cm}^{-2}\right)$ for $10 \mathrm{~min}$, conferring a cumulative release amount of 69.3\%. In contrast, the release rates of AIBI were slightly increased at $\mathrm{pH} 7.4$ under the same conditions. Consequently, the above finding confirmed that the $\mathrm{pH}$ and NIR-laser irradiation could act as an intelligent switch for the nanocomposites to control the release of AIBI, which could prevent drug leakage and reduce adverse effects to normal tissues.

\section{Biocompatibility of the NPs}

The biocompatibility of NPs is of great importance for their systemic administration as drug delivery carriers prior to their clinical application. The cytotoxicity of AHTPR to normal cells was firstly evaluated on BMSCs by using CCK8 assay, and no significant cytotoxicity could be observed even at the concentration of $480 \mu \mathrm{g} \mathrm{mL} \mathrm{m}^{-1}$ (Fig. 2h), proving the excellent biocompatibility of the materials. In addition, the hemolysis assay was also performed to assess the hemocompatibility of the NPs. As displayed in Fig. 2i, there was negligible hemolysis of RBCs in the PBS and AHTPR groups, even at the highest testing concentration $\left(800 \mu \mathrm{g} \mathrm{mL}^{-1}\right)$. In contrast, the color of the positive control (pure water) turned red because the RBCs were broken to release the hemoglobin. Collectively, the prepared AHTPR NPs showed excellent biocompatibility and hemocompatibility, making the AHTPR an outstanding candidate for future exploration.

\section{Cellular uptake and mitochondrial targeting effects}

It is essential to effective targeted delivery the therapy agents into tumors for nanomaterial-based drug-delivery systems [39]. To study the cellular uptake behavior of the NPs, the cellular uptake of free ICG and ICG-labeled NPs were determined by a fluorescence microscope. As shown in Fig. 3a, the red fluorescence intensity of ICG in MNNG/HOS cells treated with ICG@HTPR NPs was significantly stronger than that of the cells treated with ICG@HTP NPs and free ICG. Enhanced cellular uptake of the ICG@HTPR NPs might be ascribed to the capacity of the RGD peptide which can attach integrin $\alpha v \beta 3$ integrin overexpressed in OS cells. Additionally, the competitive experiment demonstrated that the intracellular fluorescence signals were markedly decreased when pre-treated with free RGD peptide (Fig. 3a), confirming that endocytosis of the RGD-modified NPs was partly ascribed to integrin receptor-mediated endocytosis pathway. Taken together, these results demonstrated that our designed RGD-functionalized nanocarriers could be efficiently internalized by MNNG/HOS cells, which provided the potential for tumor-specific drug delivery.

To further investigate the mechanism of cellular uptake, we then used the MNNG/HOS cells to incubate with ICG@HTPR NPs under different conditions. Since the uptake of nano-formulations was largely mediated through clathrin-mediated endocytosis, caveolae-mediated endocytosis, macropinocytosis, and phagocytosis [40, 41], the MNNG/HOS cells were pre-treated with different endocytosis inhibitors: the clathrin pathway inhibitor chlorpromazine, caveolae inhibitor genistein, micropinocytosis inhibitor amiloride, and phagocytosis inhibitor cytochalasin D. As shown in Additional file 1: Fig. S8, the cellular uptake of ICG@HTPR by MNNG/ HOS cells was obviously suppressed by the inhibitors of amiloride and chlorpromazine, but was not affected by cytochalasin D and genistein treatment. The results suggested that the cellular uptake of the NPs was mainly depends on macropinocytosis- and clathrin-mediated endocytosis pathways. Furthermore, internalization assays were also performed at low temperature $\left(4{ }^{\circ} \mathrm{C}\right)$ in the absence of endocytic inhibitors to reflect the energy-dependent endocytosis pathway. As displayed in Additional file 1: Fig. S8, the cell uptake efficiency of 
$\mathbf{a}$
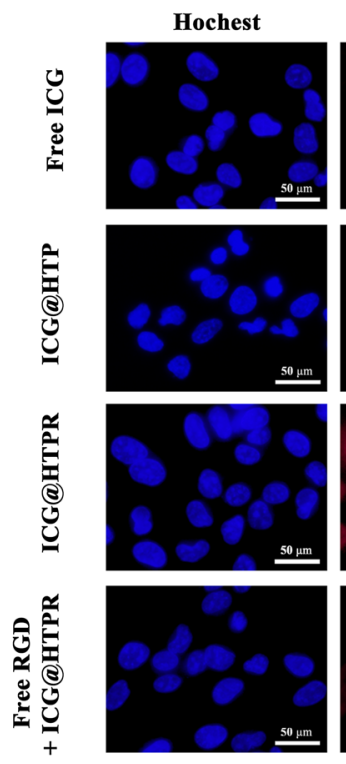

c
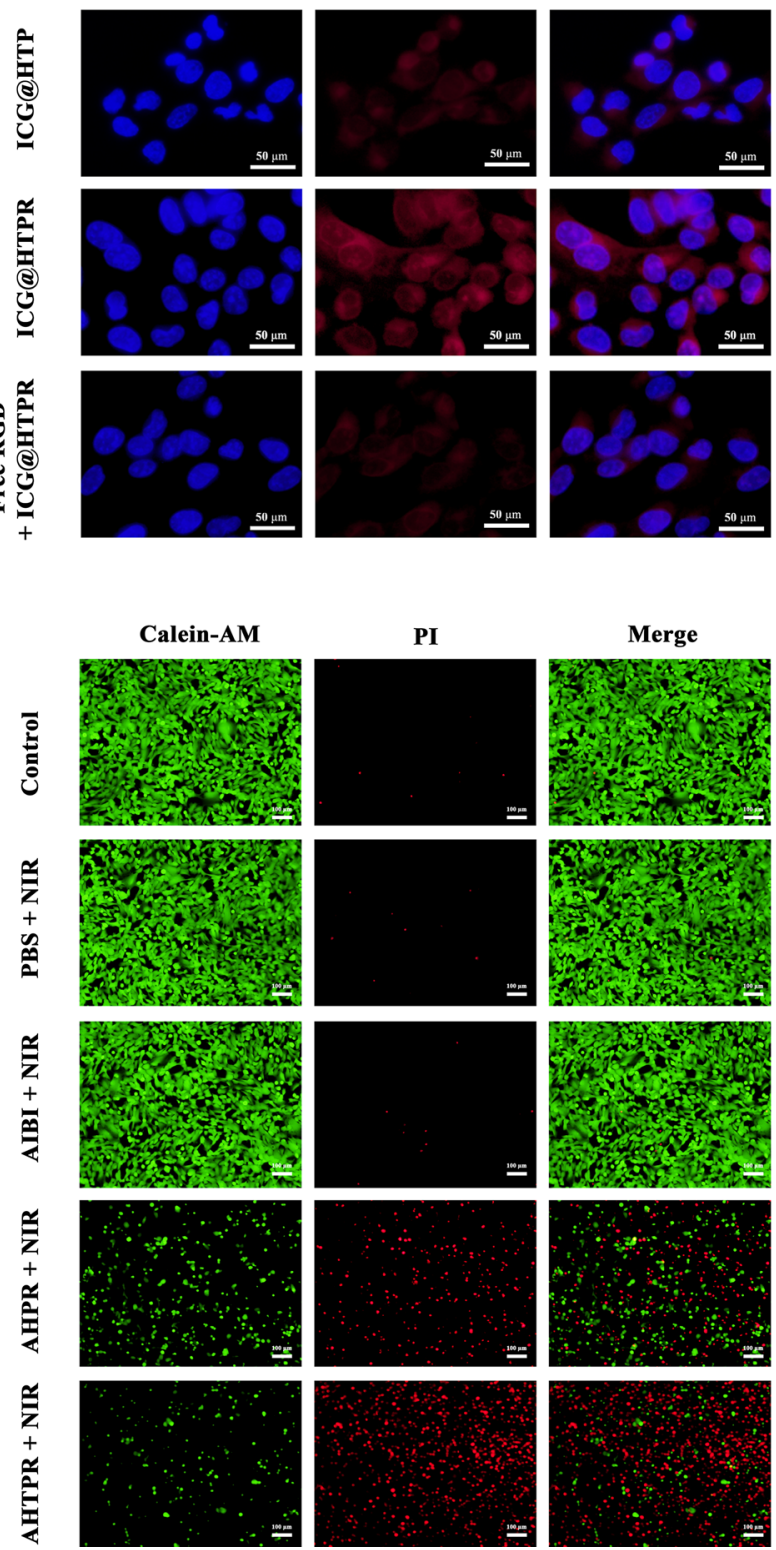

b
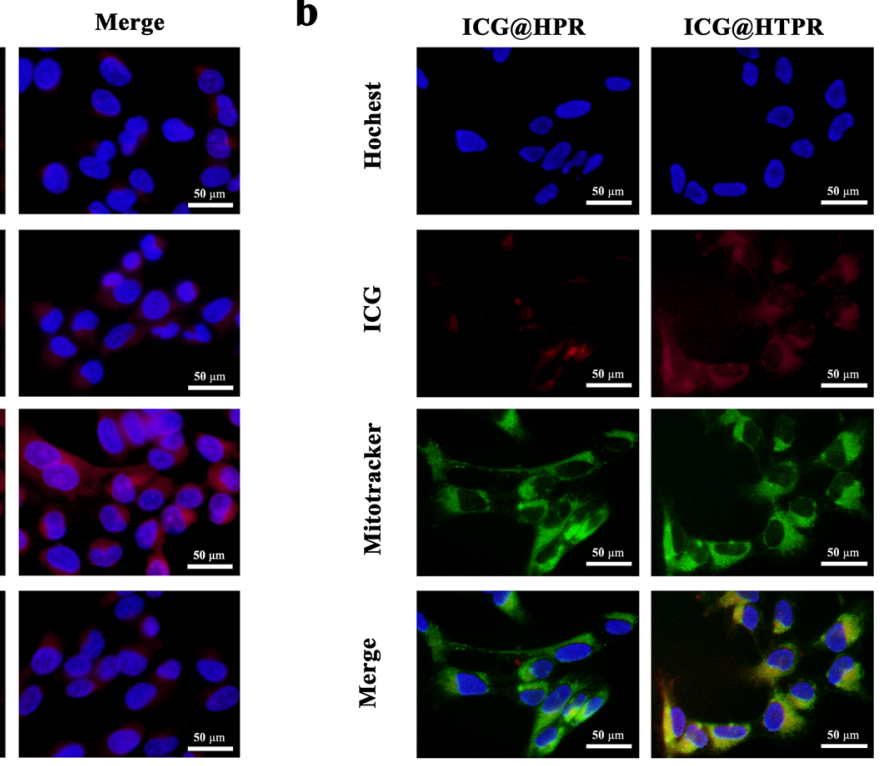

d

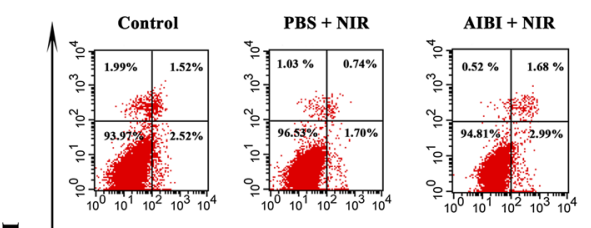

$\overline{2}$

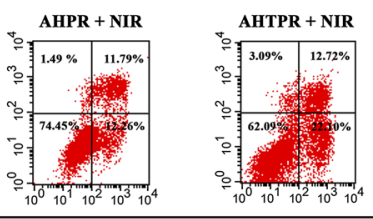

Annexin V-FITC

e

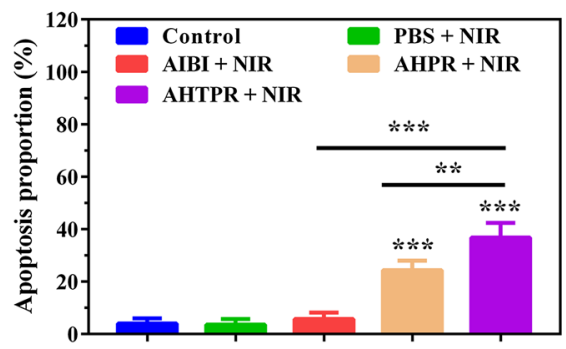

Fig. 3 In Vitro Cellular Assay. a Fluorescence microscopy images of MNNG/HOS cells after 4 h incubation with ICG, ICG@HTP and ICG@HTPR NPs. b Co-localization of the test NPs into mitochondria of MNNG/HOS cells. c Corresponding fluorescence microscopy images of MNNG/HOS cells stained with Calcein-AM and PI. d Flow cytometry apoptosis experiment based on annexin V-FITC/PI staining of MNNG/HOS cells after incubation with different formulations for $24 \mathrm{~h}$, including control group, PBS, AIBI $(50 \mu \mathrm{g} / \mathrm{mL})$, AHPR (120 $\mu \mathrm{g} / \mathrm{mL}$, equivalent AlBI dosage of $50 \mu \mathrm{g} / \mathrm{mL})$, AHTPR $(120 \mu \mathrm{g} / \mathrm{mL}$, equivalent AIBI dosage of $50 \mu \mathrm{g} / \mathrm{mL})$, and $808 \mathrm{~nm}$ laser $\left(1.0 \mathrm{~W} \mathrm{~cm}^{-2}, 5 \mathrm{~min}\right)$. Cells without treatment were used as control. e Apoptosis ratios of cells after corresponding treatment was quantified. $\left.{ }^{*} \mathrm{P}<0.05,{ }^{* *} \mathrm{P}<0.01,{ }^{* * *} \mathrm{P}<0.001\right)$ 
ICG@HTPR was more enhanced at $37{ }^{\circ} \mathrm{C}$ than at $4{ }^{\circ} \mathrm{C}$ in MNNG/HOS cells. This indicated that the uptake of NPs in MNNG/HOS cells was mainly an energy-dependent process.

According to previous studies [14, 42], ICG@HTPR NPs were expected to be localized the mitochondria due to the TPP targeting ability. The co-localization of the NPs into mitochondria was evaluated by a fluorescence microscope. As revealed in Fig. 3b, a significant red fluorescence was observed in ICG@HTPR NPs group, which was stronger than that in ICG@HPR groups, and it nearly overlapped with the green fluorescence of mitochondria. This result confirmed that the TPP functionalized NPs exhibited excellent mitochondria-targeting ability, which also demonstrated that the PDA shell could be removed to expose TPP in the acidic environment before reaching the mitochondria.

\section{In vitro cell killing evaluation}

Encourage by the excellent mitochondrial targeting ability of the NPs, the synergistic therapeutic effects of the engineered platform were assessed in vitro. Firstly, live/ dead cell staining assay was utilized to directly visualize cell death after receiving various treatments under a fluorescence microscope. As displayed in Fig. 3c, most cells in PBS + NIR group were alive as evidenced by the strong green fluorescence and undetectable red fluorescence signal, suggesting that low-temperature laser irradiation alone showed little cytotoxicity. Similarly, cells treated with free AIBI displayed almost undetectable red fluorescence signal under low-temperature laser irradiation. Although increased cells with red fluorescence were presented in the AHPR with irradiation treated group, more cells were killed in AHTPR coupled with NIR irradiation treated group were dead, confirming that the therapeutic efficacy could be improved with mitochondria-targeted treatment.

In addition, the in vitro anticancer activity was quantitatively evaluated in MNNG/HOS cells by CCK8 assay. It was found that AHTPR induced the most severe cytotoxicity to MNNG/HOS cells. Only $20.0 \%$ cells kept alive after being treated with AHTPR + NIR for $24 \mathrm{~h}$, while there were $93.1 \%$ or $43.5 \%$ of viable cells for those treated with AIBI + NIR or AHPR + NIR, respectively (Additional file 1: Fig. S9). Subsequently, we further verified the apoptosis of MNNG/HOS cells after various treatments with flow cytometry using annexin V-FITC/PI staining. Consistently, we found that AHTPR + NIR could induce a dramatically higher level of cell apoptosis (Fig. 3d, e). Collectively, these results confirmed the excellent synergistic therapeutic effect of mitochondria-targeting LPTT and TDT.

\section{Accumulation of free radicals in mitochondria induced oxidative damage}

AIBI, one of azo initiators, could be decomposed rapidly under heat stimulation to produce alkyl radicals for killing cancer cells. ESR analysis was performed to evaluate the generation of free radical in vitro. The 5,5'-dimethylpyrroline-1-oxide (DMPO) was used as a spin trap agent to capture the released radicals. As shown in Additional file 1: Fig. S10, a group of typical radical peaks appeared in the solution containing AHTPR after irradiating with the $808 \mathrm{~nm}$ laser irradiation for $5 \mathrm{~min}$. By contrast, no alkyl radical peaks were observed in the solution containing AIBI or HTPR under the same condition, suggesting that the capability of AHTPR NPs for oxygen-irrelevant free-radical generation upon laser irradiation. Subsequently, to evaluate the intracellular free-radical levels, DCFH-DA was employed to as a fluorescent probe to verify the generated capacity of intracellular free radicals. As presented in Fig. 4a and Additional file 1: Fig. S11, no green fluorescence was observed for the control group with NIR laser alone. Notably, cells treated with AHTPR + NIR exhibited distinct green fluorescence compared with other treatments under the same conditions. Such findings indicated that the precise subcellular localization of nanocomposites could dramatically enhance the free-radicals generation at a low temperature $\left(<45{ }^{\circ} \mathrm{C}\right)$. More importantly, it is well known that $\mathrm{MnO}_{2}$-based nanoplatform could effectively remit the effect of excessive GSH on counteracting the damaging effects of alkyl radicals $[12,19,43]$. To confirm this, the degradation of the as-prepared $\mathrm{H}-\mathrm{mMnO}_{2} \mathrm{NPs}$ in the presence of GSH was investigated. First, the morphologic changes of $\mathrm{H}-\mathrm{mMnO}_{2} \mathrm{NPs}$ at different GSH concentrations $(0,1$, and $2 \mathrm{mM}$, respectively) were observed by TEM. As shown in Additional file 1: Fig. S12, the hollow structure of $\mathrm{MnO}_{2}$ was almost decomposed when treated GSH with a concentration of $2 \mathrm{mM}$, proving the GSHresponsive degradation of $\mathrm{H}-\mathrm{mMnO}_{2}$. Subsequently, X-ray photoelectron spectroscopy (XPS) was used to determine the valence state of the NPs in the presence of $2 \mathrm{mM} \mathrm{GSH}$ or not. As displayed in Additional file 1: Fig. $\mathrm{S} 13$, two peaks at 641.9 and $653.6 \mathrm{eV}$ ascribed to $\mathrm{Mn} 2 \mathrm{p}_{3 / 2}$ and $\mathrm{Mn} 2 \mathrm{p}_{1 / 2}$, respectively, which demonstrated the elemental valence of $\mathrm{Mn}$ in the synthesized $\mathrm{H}-\mathrm{mMnO}_{2}$ was IV [37]. After the treatment with GSH, two major peaks for $M n 2 p_{3 / 2}$ and $M n 2 p_{1 / 2}$ were present at 641.5 and $653.2 \mathrm{eV}[44,45]$ (Additional file 1: Fig. S13b), respectively, which indicated the presence of $\mathrm{Mn}^{2+}$ valence state. From the XPS analysis, it could be seen that the elemental valence of $\mathrm{Mn}$ in the $\mathrm{H}-\mathrm{mMnO}_{2} \mathrm{NPs}$ changed from IV to II after treatment with GSH.

The GSH levels of MNNG/HOS cells after various treatment were then assessed using a GSH assay kit. As 


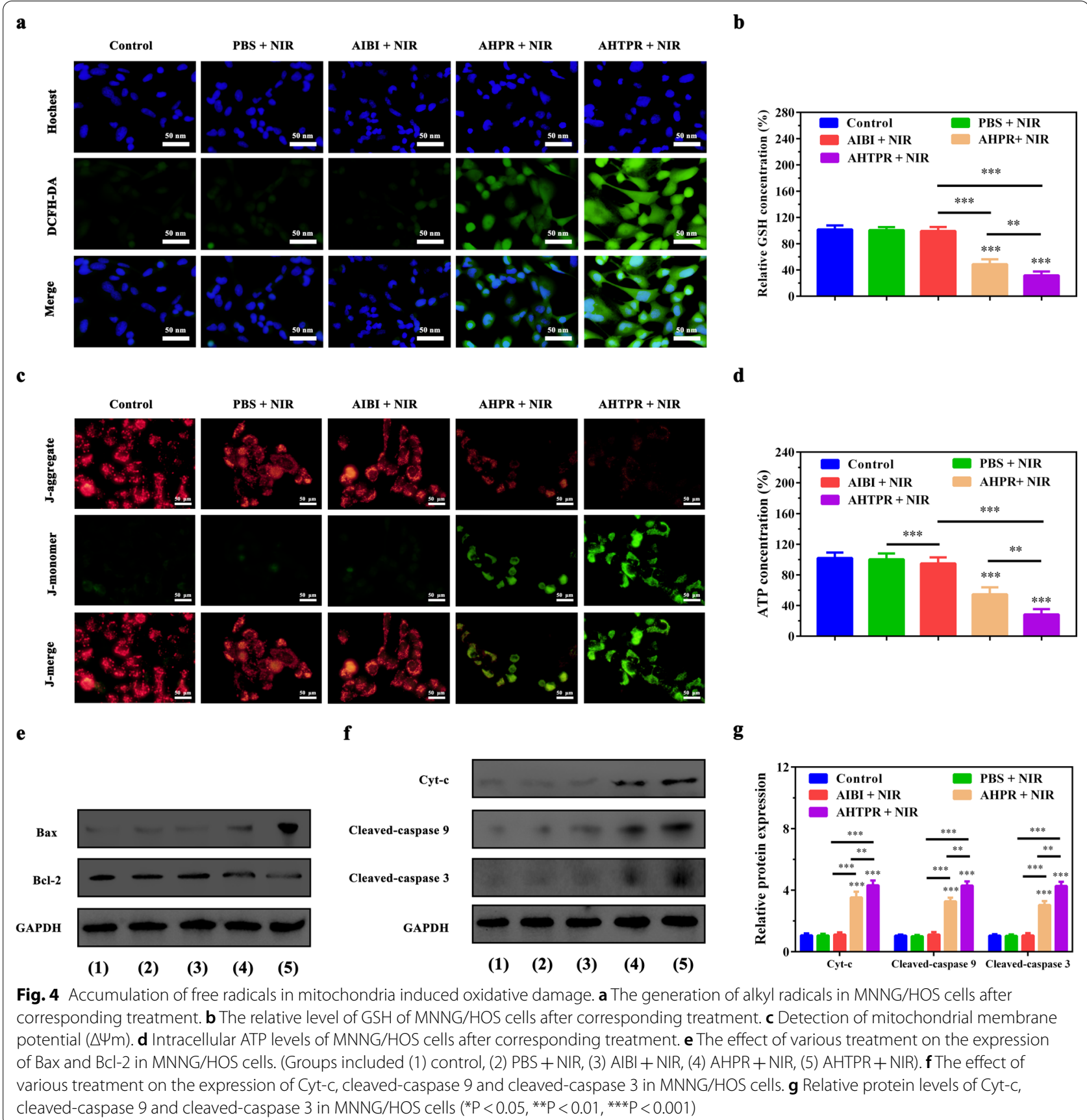

predicted, a dramatic reduction in intracellular GSH level was observed for the AHTPR + NIR group (Fig. 4b). These results illustrated that AHTPR could significantly enhance the accumulation of oxygen-irrelevant free radicals in mitochondria through the targeted release of free radicals in mitochondria and $\mathrm{MnO}_{2}$-mediated $\mathrm{GSH}$ depletion.

Since mitochondria are extremely sensitive to freeradical mediated damages, selectively accumulation of free radicals in mitochondria would trigger mitochondrial dysfunction, decrease the mitochondrial membrane potential, and finally induce tumor cell apoptosis $[14,15]$. The mitochondrial membrane potential $(\Delta \Psi \mathrm{m})$ changes after various treatments were firstly examined by performing JC-1 assays. As shown in Fig. 4c, the weakest red fluorescence was detected in AHTPR + NIR group compared with other treatments, clearly indicating a dramatic decrease in the 
mitochondrial membrane potential and the destruction of membrane integrity.

Mitochondria are recognized as the pivotal sources of ATP production to meet the energy demands of the cell [46]. Accumulating evidence has revealed that mitochondrial dysfunction would result in defective oxidative respiratory chain, which might decrease intracellular ATP levels and could not provide the required energy for tumor growth [47, 48]. Subsequently, we continued to investigate if the synergistic therapeutic effect could influence the ATP production in MNNG/HOS cells. As shown in Fig. 4d, compared with other groups, the intracellular ATP concentration decreased tremendously in AHTPR + NIR treated cells. These results indicated that mitochondria-targeting LPTT and TDT could not only disrupt mitochondrial membrane potential but also inhibit the cellular ATP production, ultimately inducing the mitochondria-mediated cell apoptosis.

To further illustrate the mitochondrial mediated apoptosis pathway, the expression of apoptosis-related proteins was investigated in MNNG/HOS cells by western-blot analysis. As revealed by western blotting (Fig. 4e) and relative quantitative analysis (Additional file 1: Fig. S14), the cells treated with AHTPR + NIR significantly upregulated the proapoptotic protein Bax and dramatically down-regulated the anti-apoptotic protein Bcl-2. Meanwhile, the expression of apoptosis protein markers (Cyt-c, cleaved-caspase- 9 and cleaved-caspase-3) were markedly increased in AHTPR + NIR group, compared with other three groups (Fig. 4f, g). Taken together, all these results above revealed that AHTPR coupled with low-temperature laser irradiation could effectively decrease mitochondrial membrane potential, reduce ATP production, and ultimately inducing mitochondrial associated apoptosis in cancer cells (Fig. 5), exhibiting the advantages of mitochondria-targeted LPTT/TDT.

\section{Biodistribution and photothermal effect in vivo}

To investigate the in vivo biodistribution of the nanocomposites, MNNG/HOS tumor-bearing mouse model was established for in vivo imaging using a small animal imaging system. As shown in Fig. 6a, the accumulated fluorescence was observed at various time intervals, demonstrating that the NPs could gradually accumulate in the tumors. The intensity of fluorescence within the tumor tissues reached a maximum after $6 \mathrm{~h}$ post-injection and decreased with the prolonged time. After $24 \mathrm{~h}$ post-injection, the tumor site still maintained the relative strong

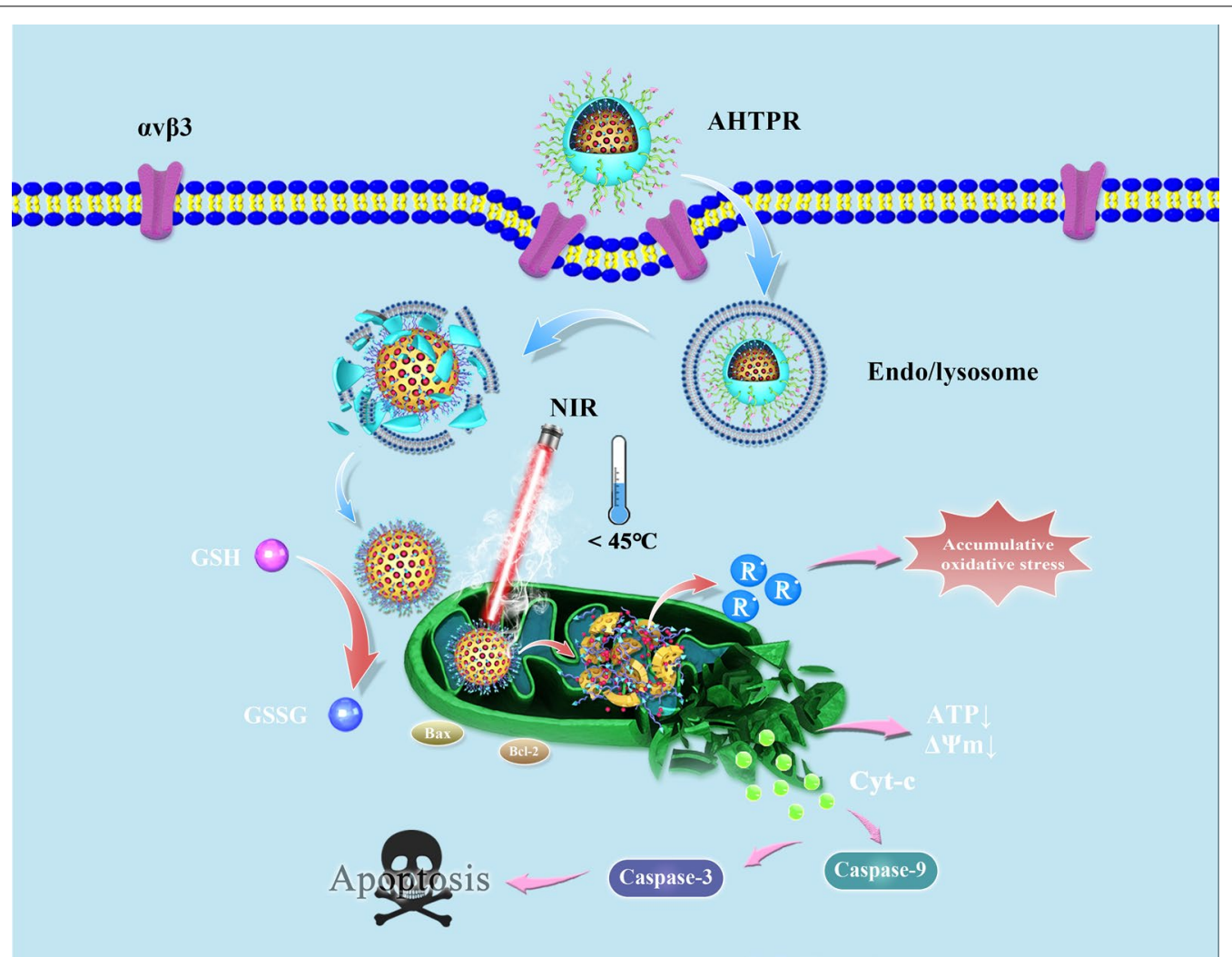

Fig. 5 Schematic illustration of the underlying mechanism for the synergistic mitochondria-targeted LPTT/TDT 


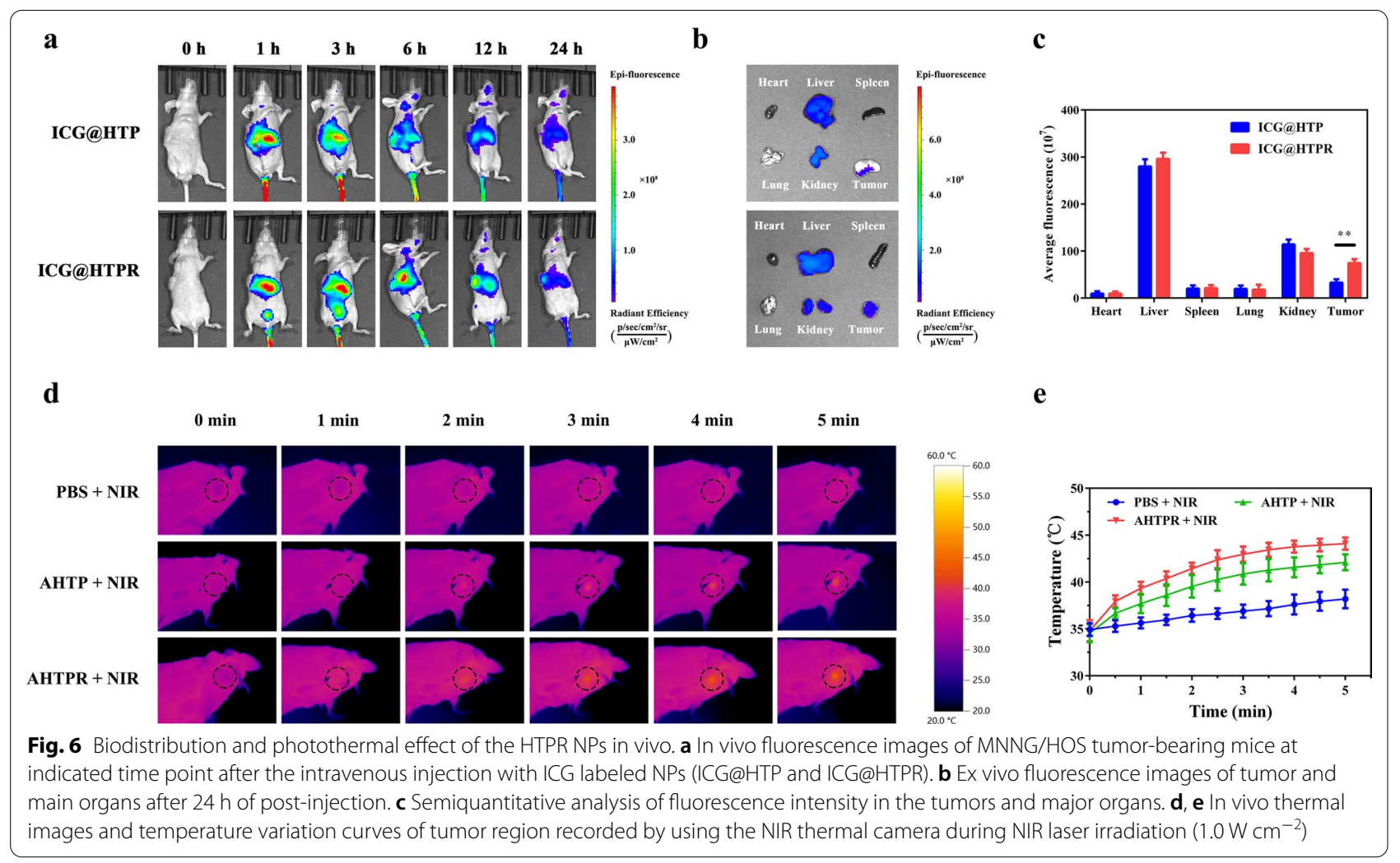

fluorescence, indicating the long retention of the NPs. Meanwhile, the tumor tissues as well as major organs (heart, liver spleen, lung and kidney) were harvested for ex vivo imaging. Notably, the fluorescence intensity in the tumor tissues was still much stronger than in the major organs by semiquantitative mean fluorescence intensity analysis (Fig. 6b, c), further confirming the superior enrichment capacity of the RGD modified NPs in tumor. The above results exhibited that the ICG@HTPR NPs could prominently accumulated in tumor region, which was owing to enhanced permeability and retention (EPR) effect-mediated passive and RGD-induced active tumortargeting delivery.

Based on the above in vivo imaging observation, we selected $6 \mathrm{~h}$ post-injection as the optimal timepoint for laser irradiation. As indicated in Fig. $6 \mathrm{~d}$ and e, the temperature in the free PBS treated mice increased slightly after $5 \mathrm{~min}$ of NIR laser irradiation. Notably, the temperature of tumor site in the AHTPR group could reach about $45{ }^{\circ} \mathrm{C}$ under the same condition, which is enough to lead the decomposition of AIBI and the release of free radicals for therapy. These results highlighted the promising photothermal performance of AHTPR in vivo.

\section{In vivo antitumor study}

Inspired by the promising in vitro therapeutic effects and excellent tumor accumulation of the as-prepared NPs, a MNNG/HOS tumor xenograft model was established to further validate the in vivo LPTT/TDT synergistic therapeutic efficacy of the nanoplatforms. The experimental process in vivo was showed in Fig. 7a. As displayed in Fig. $7 \mathrm{a}-\mathrm{d}$, the tumors of mice without treatment and mice treated with PBS + NIR grew rapidly throughout the experiment, indicating that NIR irradiation alone had little inhibitory effect on the tumor growth. Comparatively, the mice treated with AIBI + NIR and AHTP + NIR showed slight tumor growth inhibition effect while the growth of tumors on mice treated with AHTPR + NIR was noticeably controlled, which might be contributed to the precise accumulation of AHTPR in tumor compared with nonspecific AIBI. Moreover, AHTPR could significantly improve the oxygen-irrelevant free radicals-based anticancer effect through reducing the intracellular GSH levels. Unsurprisingly, the mice injected with AHTPR couple with NIR irradiation exhibited more excellent tumor growth inhibitory efficacy, suggesting that selectively generation of free radicals in mitochondria might dramatically enhance the therapeutic efficacy. Notably, no significant body weight changes were observed (Fig. 7f) in all groups during the therapy, 
$\mathbf{a}$

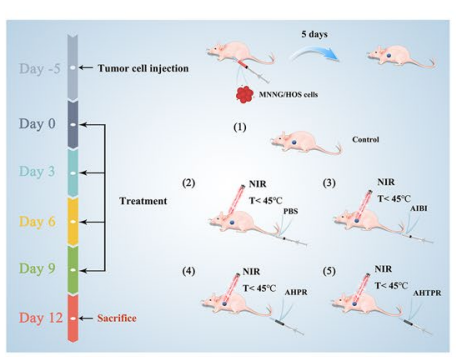

d

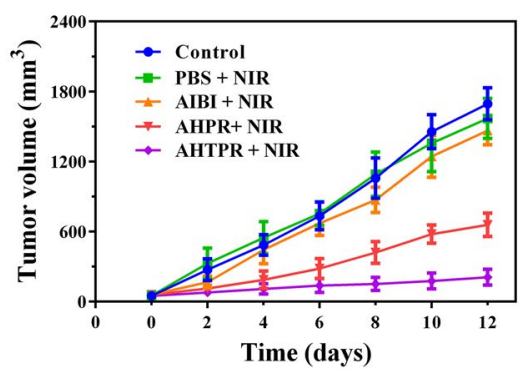

b

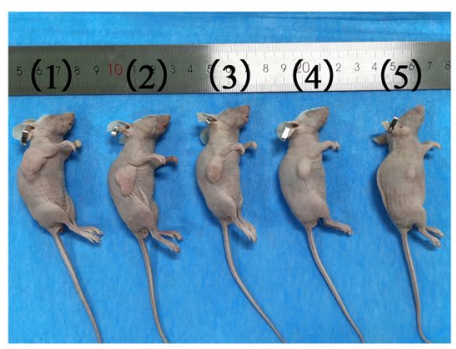

$\mathbf{e}$

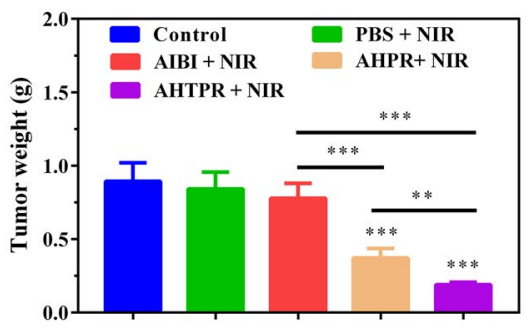

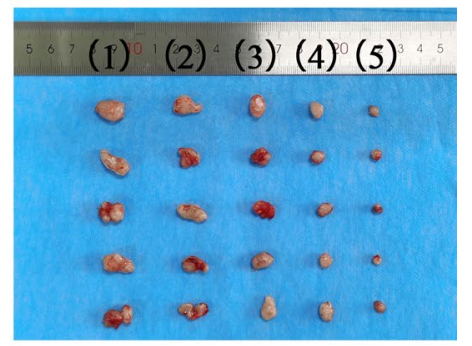

f

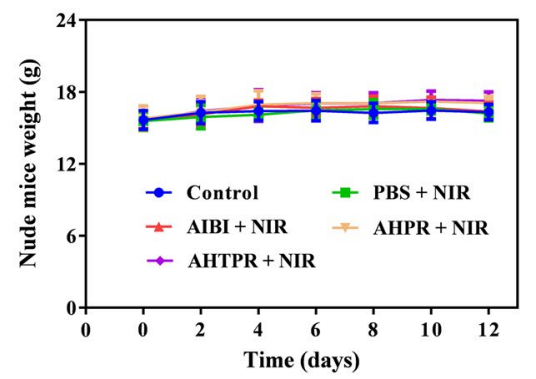

g
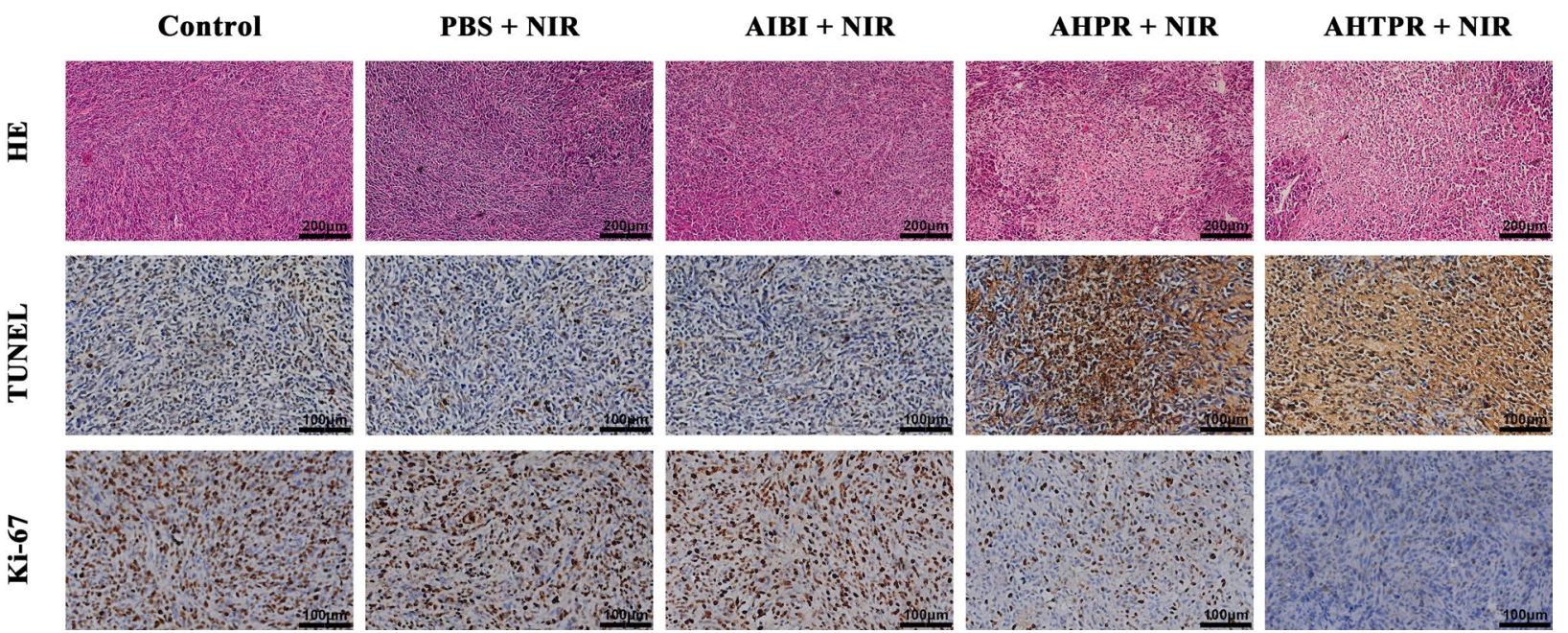

Fig. 7 Evaluation of the synergistic therapeutic efficacy of formulations in vivo. a Schematic diagram of in vivo therapy in tumor-bearing mice. b Representative photographs of tumor-bearing mice after various treatments. c The photographs of all tumors taken from mice after various treatments. (Groups included (1) control, (2) PBS + NIR, (3) AIBI + NIR, (4) AHPR + NIR, (5) AHTPR + NIR). d Tumor volume growth curves of tumor-bearing mice during the administration of different formulations. e Tumor weights were measured after various treatments. $\mathbf{f}$ Body weight changes of MNNG/HOS tumor-bearing mice in different groups during the treatment. $\mathbf{g}$ H\&E and immunohistochemical (TUNEL and Ki-67) analyses of tumor slices in different groups. $\left.{ }^{*} \mathrm{P}<0.05,{ }^{* *} \mathrm{P}<0.01,{ }^{* * *} \mathrm{P}<0.001\right)$

showing all treatments had no significant systemic toxicity to the animals.

At the end of the treatment, the tumor tissues and main organs of mice were collected for histopathological studies. As shown in Fig. 7g, the H\&E staining of tumor sections demonstrated that AHTPR + NIR group exhibited the most significant necrosis. TUNEL staining also exhibited that AHTPR + NIR group caused cell apoptosis in a significantly higher level compared with groups. Moreover, the expression of antigen Ki-67 was further investigated to evaluate the tumor cell proliferation. As expect, tumor cells in AHTPR + NIR group showed obviously lower expression of antigen Ki-67 compared to those in other groups. Additionally, the H\&E staining 
images of major organs (heart, liver, spleen, lung, and kidney) demonstrated that no noticeable tissue damage was observed in those mice with various treatments (Additional file 1: Fig. S15). Meanwhile, the levels of the hepatic and renal function markers (ALT and BUN) were all found to be normal, indicating the favorable biosafety of these therapeutic strategies (Additional file 1: Fig. S16). These results collectively validated that the designed AHTPR nanoplatforms at a low temperature laser irradiation could eradicate tumors effectively without appreciable side effects to the treated animals.

\section{Conclusion}

In summary, we successfully synthesized a biocompatible multifunctional nanoplatform composed of RGD functioned PDA as a shell and TPP modified $\mathrm{H}-\mathrm{mMnO}_{2}$ as a core (AHTPR), which could achieve synergistic anticancer performance via the combination of mitochondria targeting LPTT/TDT. The promising delivery system was featured with distinctive advantages such as RGD induced active tumor-targeting, excellent mitochondria targeting ability, $\mathrm{pH} / \mathrm{NIR}$ dual-responsive drug release, low temperature-activated alkyl radicals burst in mitochondria. The synergistic therapy efficacy was confirmed by effectively inducing cancer cell death in vitro and completely eradicating the tumors in vivo. Additionally, the excellent biosafety and biocompatibility of the nanoplatforms were confirmed both in vitro and in vivo. Taken together, the current study provides a novel paradigm toward oxygen-independent free-radical-based cancer therapy, especially for the treatment of hypoxic solid tumors.

\section{Supplementary Information}

The online version contains supplementary material available at https://doi. org/10.1186/s12951-021-01142-6.

Additional file 1: Figure S1. TEM imaging of $\mathrm{sSiO}_{2} \mathrm{NPs}$. Figure $\mathbf{S 2} . \mathrm{N}_{2}$ adsorption/desorption isotherms and pore-size distribution curve of the as-synthesized $\mathrm{H}-\mathrm{mMnO}_{2} \mathrm{NPs}$. Figure S3. EDS analysis of the AHTPR NPS. Figure S4. The dispersity and stability of the AHTPR NPS. a The dispersity of the AHTPR NPs was monitored in different media (water, a-MEM culture medium with or without 10\% FBS) over a prolonged incubation time up to 7 days. b Hydrodynamic size variation of the AHTPR NPs dispersed in water, a-MEM culture medium with or without $10 \%$ FBS. Figure S5. Temperature variation curves of the different formulations (PBS, $\mathrm{H}-\mathrm{mMnO}_{2}$, and $\mathrm{HTPR}$ ) irradiated by an $808 \mathrm{~nm}$ laser ( $\left.1 \mathrm{~W} \cdot \mathrm{cm}^{-2}, 10 \mathrm{~min}\right)$. Figure S6. Photothermal-conversion performance of AHTPR NPs. (a) Photothermal performance of AHTPR NPs aqueous solution $\left(120 \mathrm{\mu g} \mathrm{mL}^{-1}\right)$ under $808 \mathrm{~nm}$ laser $\left(1.0 \mathrm{~W} \mathrm{~cm}^{-2}\right)$ irradiation. (b) Fitted linear relationship between time and $-\ln \theta$ obtained from the cooling period of (a). Figure S7. The standard curve of AIBI determined by a UV-VIS spectrophotometer. Figure S8. The cellular uptake of ICG@HTPR NPs by MNNG/HOS cells under different conditions (chlorpromazine, genistein, amiloride, and cytochalasin D, $4^{\circ} \mathrm{C}$ ). Cells treated with ICG@HTPR NPs at $37^{\circ} \mathrm{C}$ served as the control group. ( ${ }^{*} P<0.05,{ }^{* *} P<0.01,{ }^{* * *} P<0.001$, N.S., not significant). Figure $\$$ 9. Cell viability of MNNG/HOS cells after various treatments for
24 h. Figure S10. ESR spectra of DMPO in AIBI, HTPR $\left(60 \mu \mathrm{g} \mathrm{mL}^{-1}\right)$, and AHTPR $\left(60 \mathrm{\mu g} \mathrm{mL}^{-1}\right)$ solutions under $808 \mathrm{~nm}$ laser irradiation for $5 \mathrm{~min}$. Figure S11. The corresponding surface plot images of free radicals in MNNG/HOS cells after various treatments for $24 \mathrm{~h}$. Figure S12. TEM images of $\mathrm{H}-\mathrm{mMnO}_{2}$ after exposure to different concentrations of GSH (0, 1 , and $2 \mathrm{mM}$, respectively) at $\mathrm{pH} 6$ for $30 \mathrm{~min}$. Figure S13. XPS spectrum of the $\mathrm{H}-\mathrm{mMnO}_{2} \mathrm{NPs}$ in the presence of $2 \mathrm{mM}$ GSH or not. a Mn2p spectrum of $\mathrm{H}-\mathrm{mMnO} 2 \mathrm{NPs}$. b Mn2p spectrum of $\mathrm{H}-\mathrm{mMnO}_{2} \mathrm{NPs}$ treated with $\mathrm{GSH}(2 \mathrm{mM})$ at $\mathrm{pH}$ 6.0. Figure S14. Relative protein levels of Bax and $\mathrm{BCl}-2$ in MNNG/HOS after various treatment. Figure S15. H\&E-stained images of major organs (heart, liver, spleen, lung, and kidney) of MNNG-HOS bearing mice after the various treatments. Figure S16. Biosafety evaluation by blood biochemistry test. a Serum levels of ALT (liver function index). $\mathbf{b}$ Serum levels of BUN (kidney function index).

\section{Acknowledgements}

This study was supported by the Non-profit Central Research Institute Fund of the Chinese Academy of Medical Sciences (2019PT320001), the National Key Research and Development Program of China (2016YFC1100100), the Major Research Plan of National Natural Science Foundation of China (91649204).

\section{Authors' contributions}

$\mathrm{HZH}, \mathrm{XTD}$ and QCS designed the study, conceived the experiments, and wrote the original draft. WBY, YRZ and WJL performed the experiments. SYW, ZHL and XX analyzed data. JZ and JZZ organized the figure data. ZWS, BCW and $Y Z Z$ reviewed and edited the manuscript. All authors read and approved the final manuscript.

\section{Availability of data and materials}

The datasets supporting the conclusions of this article are included within the article and its additional file.

\section{Declarations}

Ethics approval and consent to participate

All animal procedures were approved by the Institutional Animal Care and Use Committee (IACUC) at Tongji Medical College, Huazhong University of Science and Technology (IACUC Number: S2503).

\section{Consent for publication}

All authors consent to publish.

\section{Competing interests}

The authors declare that they have no conflicts of interest.

\section{Author details}

${ }^{1}$ Department of Orthopaedics, Union Hospital, Tongji Medical College, Huazhong University of Science and Technology, Wuhan 430022, China. ${ }^{2}$ School of Medicine, Nankai University, Tianjin 300071, China. ${ }^{3}$ Department of Orthopaedic Surgery, The Third Hospital of Hebei Medical University, Shijiazhuang 050051, China. ${ }^{4} \mathrm{NHC}$ Key Laboratory of Intelligent Orthopeadic Equipment, Third Hospital of Hebei Medical University, Shijiazhuang, Hebei, China. ${ }^{5}$ Collaborative Innovation Center for Advanced Organic Chemical Materials Co-Constructed by the Province and Ministry, Hubei University, Wuhan 430062, China.

Received: 29 September 2021 Accepted: 13 November 2021 Published online: 25 November 2021

\section{References}

1. Li Z-H, Chen Y, Sun Y, Zhang X-Z. Platinum-doped Prussian blue nanozymes for multiwavelength bioimaging guided photothermal therapy of tumor and anti-inflammation. ACS Nano. 2021;15:5189-200. https://doi.org/10.1021/acsnano.0c10388.

2. Wang J, Mei T, Liu Y, Zhang Y, Zhang Z, Hu Y, Wang Y, Wu M, Yang C, Zhong $X$, et al. Dual-targeted and MRI-guided photothermal therapy iron-based 
nanoparticles-incorporated neutrophils. Biomater Sci. 2021. https://doi. org/10.1039/d1 bm00127b.

3. Shi M, Fu Z, Pan W, Chen Y, Wang K, Zhou P, Li N, Tang B. A protein-binding molecular photothermal agent for tumor ablation. Angew Chem Int Ed Engl. 2021. https://doi.org/10.1002/anie.202101009.

4. Ouyang B, Liu F, Ruan S, Liu Y, Guo H, Cai Z, Yu X, Pang Z, Shen S. Localized free radicals burst triggered by NIR-II light for augmented low-temperature photothermal therapy. ACS Appl Mater Interfaces. 2019;11:38555-67. https://doi.org/10.1021/acsami.9b15009.

5. Fu Z, Williams GR, Niu S, Wu J, Gao F, Zhang X, Yang Y, Li Y, Zhu L-M. Functionalized boron nanosheets as an intelligent nanoplatform for synergistic low-temperature photothermal therapy and chemotherapy. Nanoscale. 2020;12:14739-50. https://doi.org/10.1039/d0nr02291h.

6. Ouyang B, Liu F, Ruan S, Liu Y, Guo H, Cai Z, Yu X. Localized free radicals burst triggered by NIR-II light for augmented low-temperature photothermal therapy. ACS Appl Mater Interfaces. 2019;11:38555-67. https:// doi.org/10.1021/acsami.9b15009.

7. Sun X, Liu D, Xu X, Shen Y, Huang Y, Zeng Z, Xia M, Zhao C. NIR-triggered thermo-responsive biodegradable hydrogel with combination of photothermal and thermodynamic therapy for hypoxic tumor. Asian J Pharm Sci. 2020;15:713-27. https://doi.org/10.1016/j.ajps.2019.11.007.

8. Li Q, Ren J, Chen Q, Liu W, Xu Z, Cao Y, Kang Y, Xue P. A HMCuS@MnO nanocomplex responsive to multiple tumor environmental clues for photoacoustic/fluorescence/magnetic resonance trimodal imagingguided and enhanced photothermal/photodynamic therapy. Nanoscale. 2020;12:12508-21. https://doi.org/10.1039/dOnr01547d.

9. Gao F, He G, Yin H, Chen J, Liu Y, Lan C, Zhang S, Yang B. Titania-coated 2D gold nanoplates as nanoagents for synergistic photothermal/ sonodynamic therapy in the second near-infrared window. Nanoscale. 2019;11:2374-84. https://doi.org/10.1039/c8nr07188h.

10. Liu Z, Xue Y, Wu M, Yang G, Lan M, Zhang W. Sensitization of hypoxic tumor to photodynamic therapy via oxygen self-supply of fluorinated photosensitizers. Biomacromol. 2019;20:4563-73. https://doi.org/10. 1021/acs.biomac.9b01368.

11. Ren $H_{\text {, Yang }}$, Yong J, Fang X, Yang Z, Liu Z, Jiang X, Miao W, Li X. Mitochondria targeted nanoparticles to generate oxygen and responsiverelease of carbon monoxide for enhanced photogas therapy of cancer. Biomater Sci. 2021;9:2709-20. https://doi.org/10.1039/d0bm02028a.

12. Wu S, Liu X, Ren J, Qu X. Glutathione depletion in a benign manner by MoS-based nanoflowers for enhanced hypoxia-irrelevant free-radicalbased cancer therapy. Small. 2019;15: e1904870. https://doi.org/10.1002/ smll.201904870

13. Liu Z, Wan P, Liu Z, Yang M, Li S, Wang Y, Gan Y. Photothermal generation of oxygen-irrelevant free radicals with simultaneous suppression of glutathione synthesis for an enhanced photonic thermodynamic cancer therapy. ACS Biomater Sci Eng. 2020;6:6186-94. https://doi.org/10.1021/ acsbiomaterials.0c00889.

14. Wang L, Niu X, Song Q, Jia J, Hao Y, Zheng C, Ding K, Xiao H, Liu X, Zhang $Z$, Zhang Y. A two-step precise targeting nanoplatform for tumor therapy via the alkyl radicals activated by the microenvironment of organelles. J Control Release. 2020;318:197-209. https://doi.org/10.1016/j.jconrel.2019. 10.017 .

15. Wang X-Q, Peng M, Li C-X, Zhang Y, Zhang M, Tang Y, Liu M-D, Xie B-R, Zhang $X$-Z. Real-time imaging of free radicals for mitochondria-targeting hypoxic tumor therapy. Nano Lett. 2018;18:6804-11. https://doi.org/10. 1021/acs.nanolett.8b02670.

16. Dong Z, Feng L, Chao Y, Hao Y, Chen M, Gong F, Han X, Zhang R, Cheng L, Liu Z. Amplification of tumor oxidative stresses with liposomal fenton catalyst and glutathione inhibitor for enhanced cancer chemotherapy and radiotherapy. Nano Lett. 2019;19:805-15. https://doi.org/10.1021/acs. nanolett.8b03905.

17. Zhuang H, Zhao M, Ding S, Liu L, Yuan W, Jiang L, Han X, Jiang L. Multifunctional smart yolk-shell nanostructure with mesoporous $\mathrm{MnO}(2)$ shell for enhanced cancer therapy. ACS Appl Mater Interfaces. 2020;12:3890617. https://doi.org/10.1021/acsami.0c08389.

18. X X X, Duan J, Liu Y, Kuang Y, Duan J, Liao T, Xu Z, Jiang B, Li C. Multi-stimuli responsive hollow $\mathrm{MnO}$-based drug delivery system for magnetic resonance imaging and combined chemo-chemodynamic cancer therapy. Acta Biomater. 2021. https://doi.org/10.1016/j.actbio.2021.03.048.

19. Zhuang H, Zhao M, Ding S, Liu L, Yuan W, Jiang L, Han X, Jiang L, Yi T. Multifunctional smart yolk-shell nanostructure with mesoporous $\mathrm{MnO}$ shell for enhanced cancer therapy. ACS Appl Mater Interfaces. 2020;12:3890617. https://doi.org/10.1021/acsami.0c08389.

20. Abbasi AZ, Prasad P, Cai P, He C, Foltz WD, Amini MA, Gordijo CR, Rauth AM, WU XY. Manganese oxide and docetaxel co-loaded fluorescent polymer nanoparticles for dual modal imaging and chemotherapy of breast cancer. J Control Release. 2015;209:186-96. https://doi.org/10.1016/j. jconrel.2015.04.020

21. Fan W, Bu W, Shen B, He Q, Cui Z, Liu Y, Zheng X, Zhao K, Shi J. Intelligent $\mathrm{MnO}_{2}$ nanosheets anchored with upconversion nanoprobes for concurrent $\mathrm{pH}-/ \mathrm{H}_{2} \mathrm{O}_{2}$-responsive UCL imaging and oxygen-elevated synergetic therapy. Adv Mater. 2015;27:4155-61. https://doi.org/10.1002/adma. 201405141.

22. Greene A, Hashemi J, Kang Y. Development of MnO hollow nanoparticles for potential drug delivery applications. Nanotechnology. 2021;32: 025713. https://doi.org/10.1088/1361-6528/abb626.

23. Zeng W, Zhang H, Deng Y, Jiang A, Bao X, Guo M, Li Z, Wu M, Ji X, Zeng $X$, Mei L. Dual-response oxygen-generating $\mathrm{MnO}_{2}$ nanoparticles with polydopamine modification for combined photothermal-photodynamic therapy. Chem Eng J. 2020;389: 124494. https://doi.org/10.1016/j.cej. 2020.124494

24. Chen H, Chen H, Wang Y, Bai Y, Yuan P, Che Z, Zhang L. A novel self-coated polydopamine nanoparticle for synergistic photothermal-chemotherapy. Colloids Surf B Biointerfaces. 2021;200: 111596. https://doi.org/10.1016/j. colsurfb.2021.111596.

25. Morales-Molina A, Gambera S, Leo A, García-Castro J. Combination immunotherapy using G-CSF and oncolytic virotherapy reduces tumor growth in osteosarcoma. J Immunother Cancer. 2021. https://doi.org/10.1136/ jitc-2020-001703.

26. Ludwig BS, Tomassi S, Di Maro S, Di Leva FS, Benge A, Reichart F, Nieberler M, Kühn FE, Kessler H, Marinelli L, et al. The organometallic ferrocene exhibits amplified anti-tumor activity by targeted delivery via highly selective ligands to av $\beta 3$, av $\beta 6$, or a5 $\beta 1$ integrins. Biomaterials. 2021;271: 120754. https://doi.org/10.1016/j.biomaterials.2021.120754.

27. Gong Z, Liu X, Zhou B, Wang G, Guan X, Xu Y, Zhang J, Hong Z, Cao J, Sun $X$, et al. Tumor acidic microenvironment-induced drug release of $R G D$ peptide nanoparticles for cellular uptake and cancer therapy. Colloids Surf, B. 2021;202: 111673. https://doi.org/10.1016/j.colsurfb.2021.111673.

28. Fu S, Zhao Y, Sun J, Yang T, Zhi D, Zhang E, Zhong F, Zhen Y, Zhang $S$, Zhang S. Integrin a $\beta$-targeted liposomal drug delivery system for enhanced lung cancer therapy. Colloids Surf, B. 2021;201: 111623. https:// doi.org/10.1016/j.colsurfb.2021.111623.

29. Fang Z, Sun Y, Xiao H, Li P, Liu M, Ding F, Kan W, Miao R. Targeted osteosarcoma chemotherapy using RGD peptide-installed doxorubicin-loaded biodegradable polymeric micelle. Biomed Pharmacother. 2017;85:160-8. https://doi.org/10.1016/j.biopha.2016.11.132.

30. Martinez-Velez N, Xipell E, Jauregui P, Zalacain M, Marrodan L, Zandueta C, Vera B, Urquiza L, Sierrasesúmaga L, Julián MS, et al. The oncolytic adenovirus $\triangle 24-R G D$ in combination with cisplatin exerts a potent antiosteosarcoma activity. J Bone Miner Res. 2014;29:2287-96. https://doi. org/10.1002/jbmr.2253.

31. Yang G, Xu L, Chao Y, Xu J, Sun X, Wu Y, Peng R, Liu Z. Hollow MnO as a tumor-microenvironment-responsive biodegradable nano-platform for combination therapy favoring antitumor immune responses. Nat Commun. 2017;8:902. https://doi.org/10.1038/s41467-017-01050-0.

32. Zhang Y, Khalique A, Du X, Gao Z, Wu J, Zhang X, Zhang R, Sun Z, Liu $\mathrm{Q}, \mathrm{Xu} Z$ Z, et al. Biomimetic design of mitochondria-targeted hybrid nanozymes as superoxide scavengers. Adv Mater (Deerfield Beach, Fla). 2021;33: e2006570. https://doi.org/10.1002/adma.202006570.

33. Bi D, Zhao L, Yu R, Li H, Guo Y, Wang $X$, Han M. Surface modification of doxorubicin-loaded nanoparticles based on polydopamine with $\mathrm{pH}$-sensitive property for tumor targeting therapy. Drug Deliv. 2018;25:564-75. https://doi.org/10.1080/10717544.2018.1440447.

34. Tang J, Niu L, Liu J, Wang Y, Huang Z, Xie S, Huang L, Xu Q, Wang Y, Belfiore LA. Effect of photocurrent enhancement in porphyrin-graphene covalent hybrids. Mater Sci Eng, C Mater Biol Appl. 2014;34:186-92. https://doi.org/10.1016/..msec.2013.09.008.

35. Dreyer DR, Miller DJ, Freeman BD, Paul DR, Bielawski CW. Elucidating the structure of poly(dopamine). Langmuir ACS I Surf Colloids. 2012;28:642835. https://doi.org/10.1021/la204831b.

36. Ingavle GC, Gehrke SH, Detamore MS. The bioactivity of agarose-PEGDA interpenetrating network hydrogels with covalently immobilized RGD 
peptides and physically entrapped aggrecan. Biomaterials. 2014;35:355870. https://doi.org/10.1016/j.biomaterials.2014.01.002.

37. Zhang Y, Cao Y, Gao T, Kuang Y, An Z, Mao Z, He Y, Yan J, Lu Z, Pei R. Tumor microenvironment-responsive and catalytic cascade-enhanced nanocomposite for tumor thermal ablation synergizing with chemodynamic and chemotherapy. ACS Appl Bio Mater. 2020;3:3880-93. https://doi.org/ 10.1021/acsabm.0c00042.

38. Huang J, Xu Z, Jiang Y, Law W-C, Dong B, Zeng X, Ma M, Xu G, Zou J, Yang C. Metal organic framework-coated gold nanorod as an on-demand drug delivery platform for chemo-photothermal cancer therapy. J Nanobiotechnol. 2021;19:219. https://doi.org/10.1186/s12951-021-00961-x.

39. Wu H, Chen F, You C, Zhang Y, Sun B, Zhu Q. Smart porous core-shell cuprous oxide nanocatalyst with high biocompatibility for acid-triggered chemo/chemodynamic synergistic therapy. Small. 2020;16: e2001805. https://doi.org/10.1002/smll.202001805.

40. Fu X, Shi Y, Qi T, Qiu S, Huang Y, Zhao X, Sun Q, Lin G. Precise design strategies of nanomedicine for improving cancer therapeutic efficacy using subcellular targeting. Signal Transduct Target Therapy. 2020;5:262. https:// doi.org/10.1038/s41392-020-00342-0.

41. Lundquist P, Artursson P. Oral absorption of peptides and nanoparticles across the human intestine: opportunities, limitations and studies in human tissues. Adv Drug Deliv Rev. 2016;106:256-76. https://doi.org/10. 1016/j.addr.2016.07.007.

42. Wang H, Shi W, Zeng D, Huang Q, Xie J, Wen H, Li J, Yu X, Qin L, Zhou Y. pH-activated, mitochondria-targeted, and redox-responsive delivery of paclitaxel nanomicelles to overcome drug resistance and suppress metastasis in lung cancer. J Nanobiotechnol. 2021;19:152. https://doi.org/ 10.1186/s12951-021-00895-4.

43. Gu D, Liu Z, Wu H, An P, Zhi X, Yin Y, Liu W, Sun B. Dual catalytic cascaded nanoplatform for photo/chemodynamic/starvation synergistic therapy.
Colloids Surf, B. 2021;199: 111538. https://doi.org/10.1016/j.colsurfb.2020. 111538.

44. Wu Q, Jiang M, Zhang X, Cai J, Lin S. A novel octahedral MnO/RGO composite prepared by thermal decomposition as a noble-metal free electrocatalyst for ORR. J Mater Sci. 2017;52:6656-69. https://doi.org/10 1007/s10853-017-0901-4.

45. Zhang C, Wang J-G, Jin D, Xie K, Wei B. Facile fabrication of $\mathrm{MnO} / \mathrm{C}$ coreshell nanowires as an advanced anode material for lithium-ion batteries. Electrochim Acta. 2015;180:990-7. https://doi.org/10.1016/j.electacta. 2015.09.050.

46. Javadov S, Jang S, Chapa-Dubocq XR, Khuchua Z, Camara AK. Mitochondrial respiratory supercomplexes in mammalian cells: structural versus functional role. J Mol Med (Berl). 2021;99:57-73. https://doi.org/10.1007/ s00109-020-02004-8.

47. Guo W, Chen Z, Chen J, Feng X, Yang Y, Huang H, Liang Y, Shen G, Liang Y, Peng $C$, et al. Biodegradable hollow mesoporous organosilica nanotheranostics (HMON) for multi-mode imaging and mild photo-therapeuticinduced mitochondrial damage on gastric cancer. J Nanobiotechnol. 2020;18:99. https://doi.org/10.1186/s12951-020-00653-y.

48. Molina JR, Sun Y, Protopopova M, Gera S, Bandi M, Bristow C, McAfoos T, Morlacchi P, Ackroyd J, Agip A-NA, et al. An inhibitor of oxidative phosphorylation exploits cancer vulnerability. Nat Med. 2018;24:1036-46. https://doi.org/10.1038/s41591-018-0052-4.

\section{Publisher's Note}

Springer Nature remains neutral with regard to jurisdictional claims in published maps and institutional affiliations.
Ready to submit your research? Choose BMC and benefit from:

- fast, convenient online submission

- thorough peer review by experienced researchers in your field

- rapid publication on acceptance

- support for research data, including large and complex data types

- gold Open Access which fosters wider collaboration and increased citations

- maximum visibility for your research: over 100M website views per year

At BMC, research is always in progress.

Learn more biomedcentral.com/submissions 